ARCHIVO ESPAÑOL DE ARTE, LXXXI, 324

OCTUBRE-DICIEMBRE 2008, pp. 333-356

ISSN: 0004-0428

\title{
II. MEZQUITA DE CÓRDOBA. 'ABD AL-RAHMĀN I (169/785-786). EL TRAZADO PROPORCIONAL DE LA PLANTA Y ALZADO DE LAS ARQUERÍAS DEL ORATORIO. LA QIBLA Y EL MIHRĀB DEL SIGLO VIII
}

\author{
POR \\ ANTONio FERnÁndEZ-Puertas \\ Universidad de Granada
}

La planta de la mezquita del siglo VIII era un cuadrado dividido en dos áreas rectangulares iguales, el patio y el oratorio. El alarife dividió este último en dos cuadrados y tomó los lados opuestos de cada uno a E. y O. como radios y, al entrecruzarlos, consiguió el ancho de la nave central. Distribuyó en cinco partes iguales el área restante de cada cuadrado y obtuvo el ancho de las naves laterales. Para hallar la ubicación de las columnas pudo utilizar dos sistemas, o una cuadrícula rectangular o una retícula romboidal. Conocidos los centros de los ejes de las columnas, trazó el alzado de las arquerías y armadura mediante escuadra $(=\sqrt{ } 2)$, cartabón $(=\sqrt{ } 4)$ y escuadra menor. El muro de la qibla era corrido en las 11 naves y albergó el nicho del mihrāab.

Palabras clave: Proporción; Arte; Arquitectura musulmana; Mezquita de Córdoba; Omeyas de alAndalus.

The square ground plan of the $8^{\text {th }}$-century Mosque was divided into two equal rectangles, to form the patio and the oratory. The architect divided the oratory into two squares, took its E. and W. sides as radiuses, and the point where they crossed over gave him the width of the central nave. He divided the remaining areas of each square into five equal parts to obtain the lateral naves. To establish the place of the columns he may have used either a rectangular grid or a rhomboidal grid. With the central axes of the columns known, he elevated the arcades and the ceiling by using a set-square of $90^{\circ}, 45^{\circ}, 45^{\circ}$ (with hypotenuse $\sqrt{2}$ ), and another set-square of $90^{\circ}, 60^{\circ}, 30^{\circ}$ (with hypotenuse $\sqrt{ } 4$ ). The wall of the qibla ran the length of the 11 naves and contained the niche of the mihräb.

Key words: Proportion; Art; Muslim architecture; Mosque of Cordoba; Umayyads of al-Andalus. 
En un trabajo anterior publicado en esta Revista me ocupé del trazado proporcional general de la planta de la mezquita de Córdoba ${ }^{1}$. En este lugar continúo mis estudios monográficos sobre este monumento, con el objeto de escribir una obra general de la mezquita en época emiral y califal $^{2}$. Se analiza aquí el trazado proporcional de la planta que da la amplitud de las once naves del oratorio del siglo VIII y la exacta colocación de todas las columnas reutilizadas. Éste será el sistema proporcional que seguirán las ampliaciones del santuario hacia el S. en el siglo IX por 'Abd al-Raḥmān II y en el siglo X por al-Hakam II. Después de exponer el modo de obtención de las arquerías en la planta, se hace un breve resumen de cómo se efectuó su elevación, ya que de esto se ha tratado en detalle en un estudio previo, mencionado en la nota 2.

El alarife de 'Abd al-Raḥmān I hubo de diseñar en primer lugar la planta y alzados a escala, en papel. Tras hacer tabula rasa con los edificios preexistentes en dicho lugar, pasó a trazar la planta a tamaño natural sobre el terreno con cal o tierra de color, para que los obreros, canteros, albañiles, carpinteros y demás personal pudieran trabajar sin equivocaciones, en particular en la elevación de las arquerías sobre columnas. En el diseño de la planta sobre el terreno se utilizarían cuerdas tensas atadas a estacas, o varas de hierro, bien alineadas después de medir sus ángulos, que dan los ejes y puntos exactos requeridos en el trazado proporcional.

El alarife había fijado el ancho del muro perimetral del patio y santuario en $114 \mathrm{~cm}$., o sea, 2 codos y $1 / 4$ de otro mä'mūní aproximadamente. Esta misma anchura tienen los pilares en "T" que separan el oratorio del patio, sin contar su prolongación hacia el santuario (fig. 1; planta F. Hernández Giménez). Al mismo tiempo que se edificaba el muro perimetral se levantaban todos los contrafuertes del edificio: los estructurales del muro de la qibla y de la fachada de arcos al patio, y los decorativos de los muros E. y O. del santuario. Estos últimos sirven de fuelle para dividir los paramentos de naciente y poniente en tres unidades cuadradas, al tener su ancho igual a su alto, sin contar el friso de almenas de remate.

El arquitecto proyectó el santuario con una sola puerta de acceso desde la calle en el tramo central de los tres de poniente, la Bāb al-Uzarā' o Puerta de los Ministros (hoy llamada Puerta de San Esteban), para el acceso directo del emir y su corte al oratorio tras salir del alcázar y cruzar la calle, con las abluciones hechas y evitar el peligro de mezclarse con la gente y sufrir cualquier altercado. El lado de naciente del santuario, según mostró la excavación de F. Hernández Giménez en 1932-1934, no tuvo puerta de ingreso desde la calle en el siglo VIII, aunque sus contrafuertes están en la misma ubicación que sus homólogos de poniente. El muro exterior perimetral y los contrafuertes, bien trabados, estuvieron estucados y fingían sillares blancos con tendeles de color almagra que no coinciden con el despiece real de la sillería, lo que ocurrió en toda la mezquita y continuó en la posterior arquitectura hispanomusulmana hasta lo nazarí. Así encontró Félix Hernández Giménez restos del revestimiento original, aparecidos en la excavación del lado de naciente de la mezquita del siglo VIII.

\footnotetext{
1 Antonio Fernández-Puertas, "I. Mezquita de Córdoba. Trazado proporcional de su planta general (siglos VIIIX)", en Archivo Español de Arte, CSIC, Departamento de H. ${ }^{a}$ del Arte “Diego Velázquez", Instituto de Historia, n. ${ }^{\circ} 291$, Madrid, 2000, pp. 217-247, figs. 1-16.

2 He publicado hasta ahora los siguientes trabajos: "La decoración de las ventanas de la Bāb al-Uzarā' según dos dibujos de don Félix Hernández Giménez" en Cuadernos de la Alhambra, 15-17, Granada 1979-1981, pp. 165-210, figs. 1-56, láms. I-XXVIII. "Spain and North Africa", en The Mosque. History, Architectural Development \& Regional Diversity, edited by Martin Frishman and Asan-Uddin Khan. Thames \& Hudson, London 1995, pp. 101-117. "Uno de los dos trazados proporcionales de la Bāb al-Uzarā”," en Miscelánea de Estudios Árabes y Hebraicos, Sección Árabe-Islam, vol. 48, Universidad de Granada, 1999, pp. 59-104, figs. 1-34, láms. I, II. "Las arquerías de las naves de la mezquita de "Abd al-Rahmān I (168/786)", en Actas del XIII Congreso Nacional de Historia del Arte. Ante el nuevo milenio: raíces culturales, proyección y actualidad del arte español. Granada, 31 de octubre-3 de noviembre de 2000, volumen I, pp. 25-48, figs. 1-8.
} 


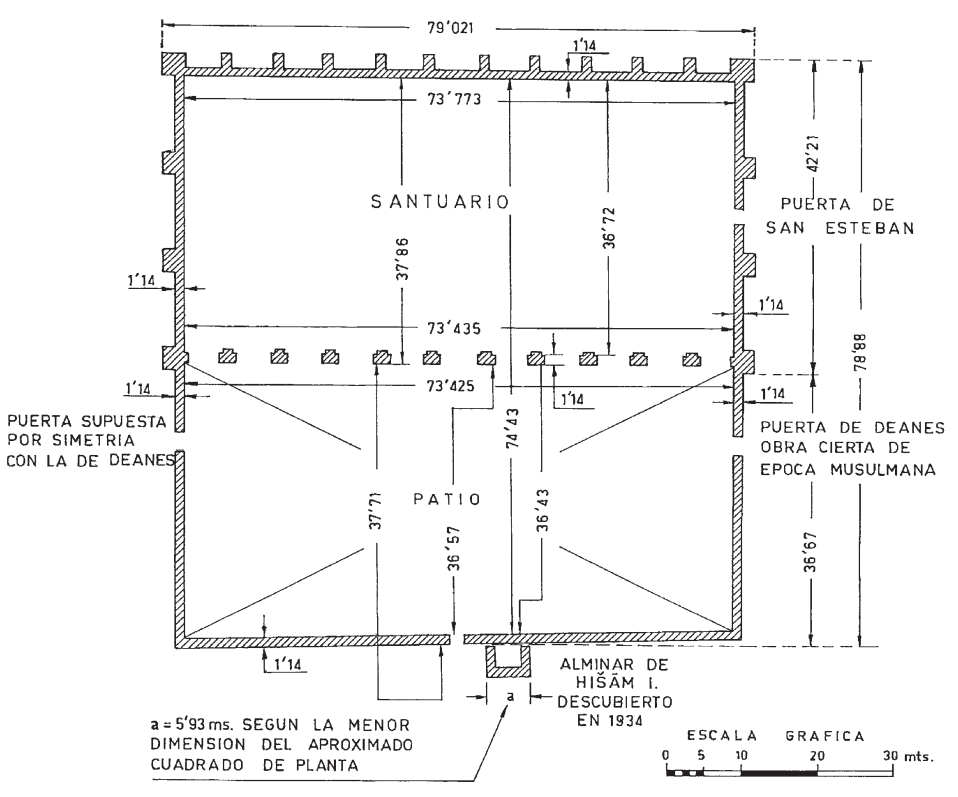

Fig. 1

Según F. Hernández Jiménez, el vano original de la Puerta de los Deanes que da acceso al patio desde el lado O. es del siglo $\mathrm{VIII}^{3}$, porque los sillares de su cantería se traban y tienen las dimensiones de los del muro perimetral de la mezquita del siglo VIII. Se ve la unión con los sillares de menor tamaño del siglo $\mathrm{X}$ en la proximidad de la jamba izquierda a $\mathrm{N}$. de esta puerta, que son de época de 'Abd al-Raḥmān III cuando amplió el patio.

En el lado opuesto E. del patio hubo de haber otra puerta similar para dar ingreso a la mezquita a los fieles desde el lado de naciente de la ciudad (aparece dibujada en las figs. 1, 2), y, por supuesto, la que con seguridad existía en el paramento N. del patio a eje con la nave central del santuario, a la que luego el emir Hišām I, hijo de 'Abd al-Raḥmān I, le construyó en su lado O. un alminar-sawmu 'a- cuadrado en unión con el muro perimetral del 169/785-786 de la mezquita de 'Abd al-Rạ̣mān I.

Al edificar en el muro de la qibla los diez contrafuertes de las correspondientes galerías se construyeron los arranques de los arcos que descansan en ellos. Al hacer los contrafuertes en "T" hacia el patio se les adosó la respectiva columna y arranque del arco de herradura en cada una de las diez galerías (figs. 2-9; lám. I).

Primero se edificó en toda su altura los muros perimetrales a S., E. y O., con los contrafuertes, la Bāb al-Uzarā' y la arquería-fachada que separa el oratorio del patio a N. Después se procedió a construir las diez arquerías del oratorio sobre columnas con basas, fustes, capiteles y cimacios de acarreo de edificios demolidos de época romana, paleocristianobizantina y visigoda (láms. I, II). Todo este enorme material reaprovechado se ordenó de manera que muestra uniformidad en la nave central axial, la cual se va perdiendo conforme

\footnotetext{
${ }^{3}$ Manuel Gómez-Moreno Martínez opinó que la Puerta de los Deanes data del siglo IX. Véase, El arte árabe español hasta los almohades. Arte mozárabe, Ars Hispaniae III, Ed. Plus Ultra, Madrid, 1951, pp. 56, 59, fig. 77. Esta opinión sigue Leopoldo Torres Balbás en Arte hispanomusulmán. Hasta la caída del califato de Córdoba, en Historia de España dirigida por Ramón Menéndez Pidal, V, 2. ${ }^{a}$ ed., Madrid, 1965, p. 394, notas 64, 65.
} 
se aproxima a las naves extremas, una y once ${ }^{4}$. Esta labor se realizaría en el recinto del patio donde se colocaron los distintos elementos de las columnas, ya con cierto orden, en diez filas, correspondientes a las respectivas arquerías del santuario en las cuales iban a ser situados al construirlas.
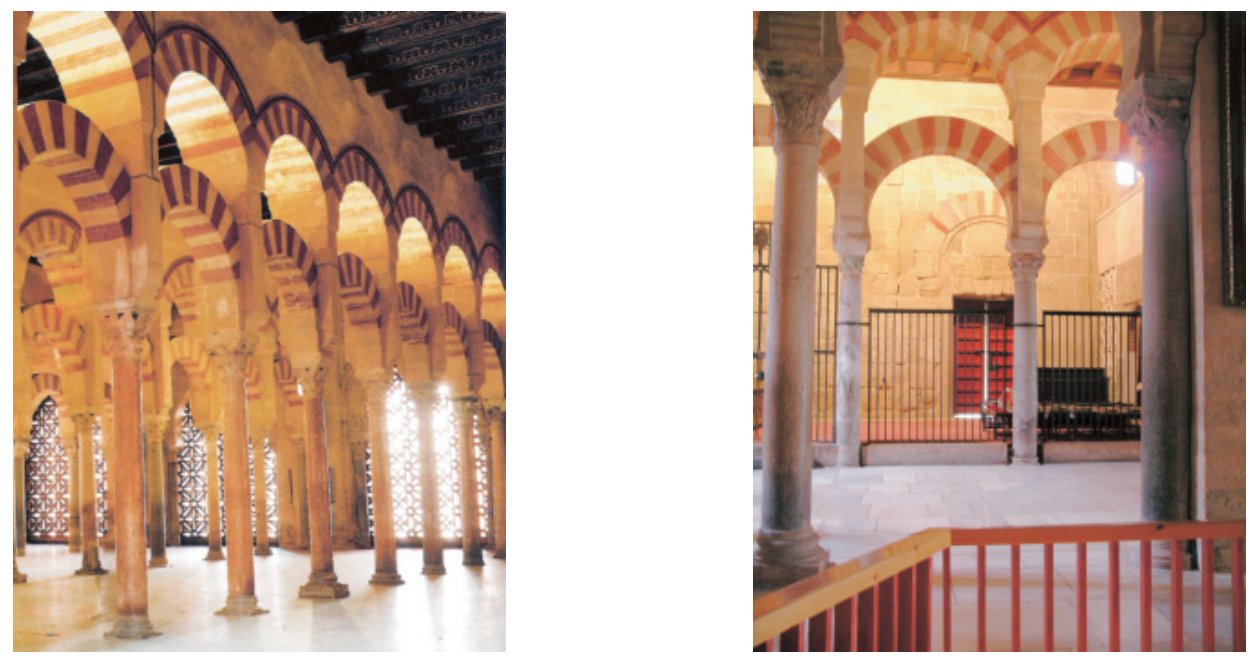

Lám. I. Mezquita de Córdoba. 'Abd al-Raḥmān I. Vista desde la nave central hacia las laterales de O. (Foto L. Esteban y M. Pijoan).

Lám. II. Mezquita de Córdoba. 'Abd al-Raḥmān I. Vista desde la excavación de época romano-paleocristiana en la nave tercera hacia la fachada interior de la Bāb al-Uzarā' (Foto P. Marinetto Sánchez).

\section{El trazado reticular proporcional del área del santuario}

Como he dicho, el alarife tenía hecho en planos todo el trazado de la mezquita en planta y alzado. Luego, al dibujarla a tamaño natural sobre el terreno, pudo fijar con total precisión el ancho de las once naves y el emplazamiento exacto de los ejes centrales de las columnas, cualquiera que fuese el variable ancho de los fustes. En el trabajo anterior publicado en esta Revista ${ }^{5}$, expliqué que la planta del santuario del siglo VIII es un rectángulo $\sqrt{ } 4$, o doble cuadrado. El patio es otro rectángulo análogo.

Ahora se describe el proceso del trazado proporcional de la planta y alzado del área del santuario, para lo que me baso en la magnífica planta efectuada por F. Hernández Giménez en

\footnotetext{
${ }^{4}$ Ya he apuntado esta peculiaridad en otro lugar, y ha sido estudiada en la disposición de los capiteles por Patrice Cressier, "Les Chapitaux de la Grande Mosquée de Cordoue", en Bulletin d'Archéologie Marocaine, Rabat, 1981, pp. 253-301; "Les Chapitaux de la Grande Mosquée de Cordoue (oratoires d'Abd al-Raḥmān I et d'Abd al-Raḥmān II) et la sculture des chapitaux à l'époque émirale", première partie (Tafel 72-82) en Madrider Mitteilungen, 25, 1984, pp. 216-281. A. FernándeZ-Puertas, "Las arquerías de las naves", pp. 33, nota 34.

5 A. FernÁndez-Puertas, "I. Mezquita de Córdoba. Trazado proporcional”, pp. 224-225, fig. 4.
} 
dos hojas ${ }^{6}$. La del patio no la llegó a hacer. Manuel López Reche ha hecho de la primera hoja un calco y los correspondientes planos a tinta que están en mi archivo particular y aquí publico (figs. 3-9). Los pasos del trazado proporcional reticular fueron los siguientes:

1) Lo primero que el arquitecto hizo fue dividir el rectángulo V4 del solar destinado a oratorio en dos cuadrados (fig. 2), a los que trazó sus diagonales sin sustraerle aún el ancho del muro perimetral de los paramentos E., O. y S. (fig. 3).

2) Luego a cada cuadrado le restó el ancho de sus correspondientes muros perimetrales de E. y O. y el común S., es decir, un ancho de $114 \mathrm{~cm}$., o sea, 2 codos mä'müníes y 1/4 de otro (fig. 4).

3) A continuación tomó como radio el lado de los cuadrados, y, desde los cuatro ángulos exteriores, trazó los correspondientes arcos de circunferencia que se cruzan entre sí en cada cuadrado. La distancia que queda entre ambos cruces es el ancho de la nave central de las once que tiene el santuario (fig. 5).

4) Seguidamente el alarife dividió en cinco partes iguales la distancia desde la nave axial central a la cara exterior del muro perimetral y obtuvo el ancho de las naves (fig. 6). La una y once resultan más estrechas que las otras ocho intermedias y la central, pues en su trazado el alarife incluyó el ancho del muro perimetral a E. y O., como se ha dicho en el paso 2 del proceso.

5) Hecho esto, tomó las distancias desde los dos centros donde se cruzan los cuatro radios de circunferencia del paso 3 (fig. 7). Las prolongó de manera longitudinal hasta los puntos de encuentro con las diagonales de los dos cuadrados del paso 1, y estas distancias las dividió en cinco partes iguales hacia N. y hacia S. (fig. 7). Tras ello prolongó estas cinco divisiones de modo horizontal hacia los muros E. y O. y formó una retícula rectangular, en cuyos ángulos se encuentran las columnas ubicadas a la perfección por el eje de sus plantas (fig. 7).

6) Otro sistema para situar con precisión las columnas, consiste en dividir en cuatro partes iguales el ancho de las cinco naves a cada lado de la central (fig. 8). En las naves una y once la parte 4 cae en el grueso del muro perimetral de modo holgado.

7) Desde estas divisiones en 4 del ancho de las naves se trazan líneas con el cartabón a $60^{\circ}$ hacia la derecha y luego hacia la izquierda, por lo que se obtiene una perfecta red rómbica (fig. 9). Las columnas de una misma arquería están separadas la distancia del largo de un rombo de la trama. En la nave central la separación en anchura entre las dos arquerías que la definen es del ancho de cuatro rombos y parte de otro, debido al trazado proporcional inconmensurable. En las ocho naves colaterales la distancia entre sus galerías es el ancho de cuatro rombos. En las naves una y once la distancia hasta el muro perimetral es la anchura de tres rombos y parte de otro (fig. 9).

La trama rómbica se encuentra cortada tanto en la línea de los contrafuertes en " $\mathrm{T}$ " de la arquería hacia el patio, como en el muro corrido de la qibla, donde los arcos arrancan desde la línea de impostas y dejaban una enorme diafanidad al muro corrido con el nicho del mịhrāb, el cual estaba hecho en el grosor de los sillares, sin sobresalir al exterior, como ha mostrado la excavación de F. Hernández Giménez (figs. 2, 16).

\footnotetext{
${ }^{6}$ Ha sido publicada por Manuel Nieto Cumplido y Carlos LuCa de Tena y Alvear en La mezquita de Córdoba. Planos y dibujos, Colegio Oficial de Arquitectos de Andalucía occidental, Córdoba, 1992, p. 70. Dibujo 112. Los dos grandes originales, hechos en papel tela por la mano del propio arquitecto, fueron donados por él, dentro de sus fundas tubulares de plomo, al Cabildo de la Catedral de Córdoba. Estas fundas las realizó no sólo para proteger los dos planos de la humedad, el roce y la luz, sino también de la metralla que durante la guerra de 1936-1939 pudiera haber entrado en su casa en Córdoba, en la calle Claudio Marcelo, 17, 2. ${ }^{\circ}$ der. Los planos los acabó bastante después, pero no tuvo tiempo de realizar la hoja correspondiente al patio de la mezquita y su alminar, aunque lo tenía todo bien croquizado y medido en una libreta.
} 


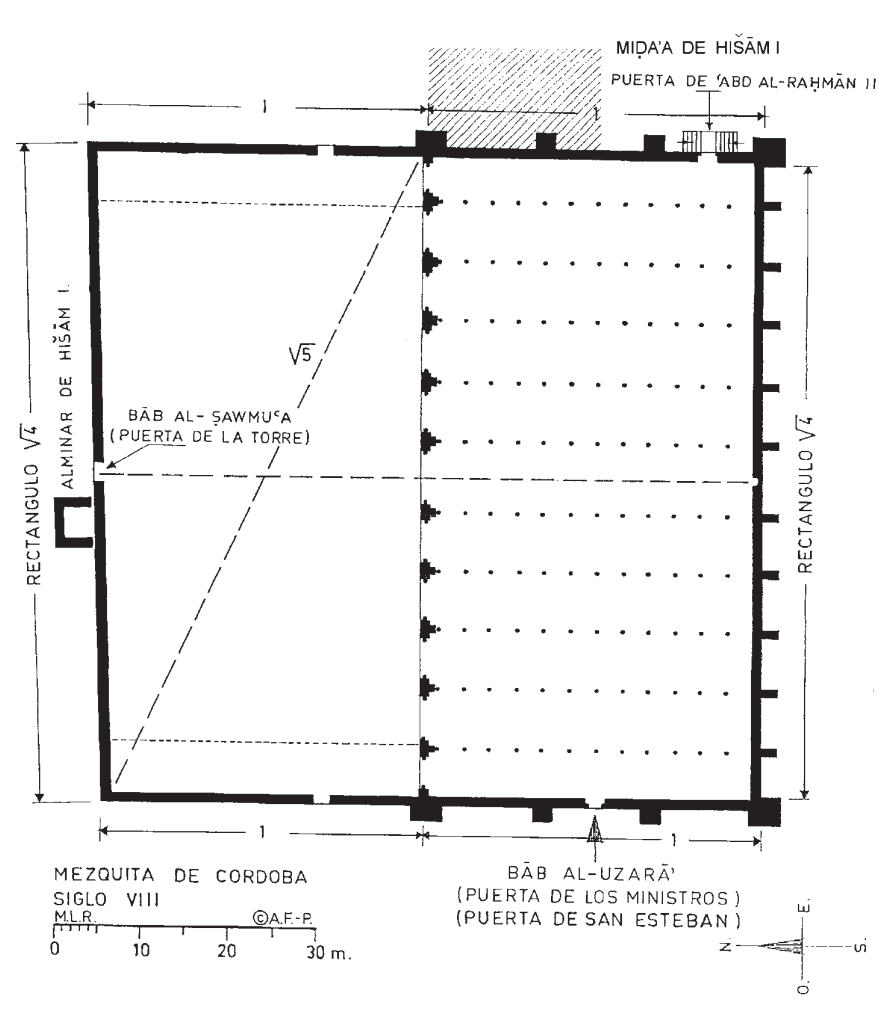

$\therefore \quad \therefore \quad \div$

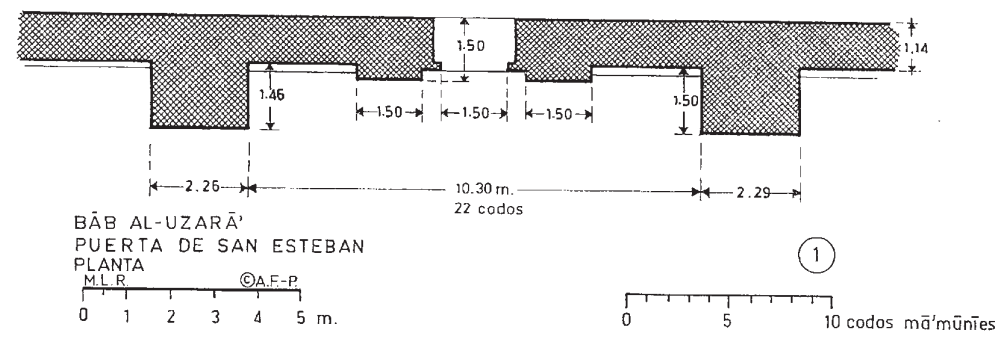

Fig. 2 


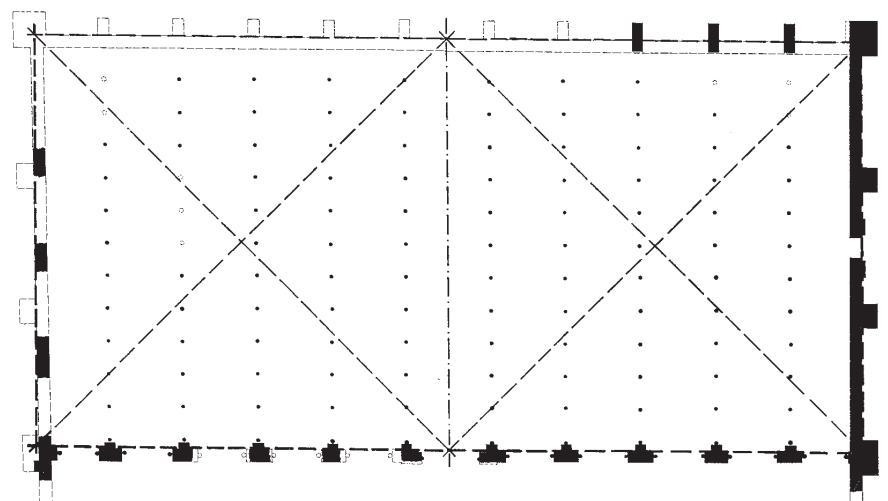

Fig. 3

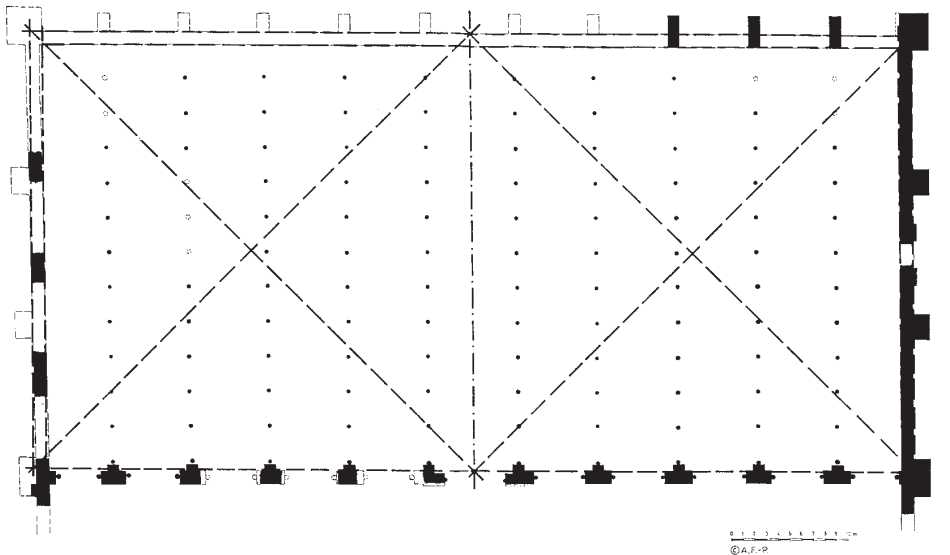

Fig. 4

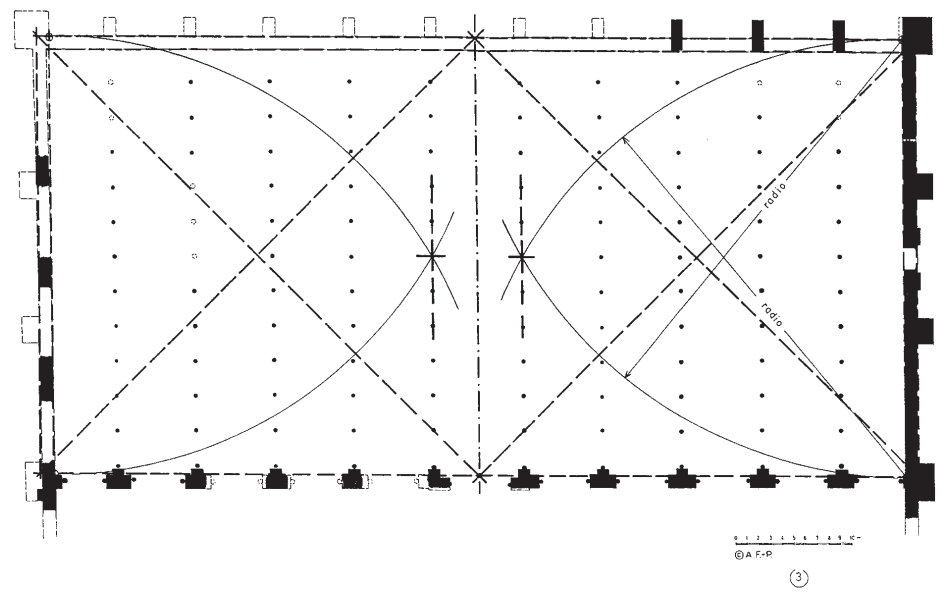

Fig. 5

AEA, LXXXI, 324, OCTUBRE-DICIEMBRE 2008, 333-356, ISSN: 0004-0428 


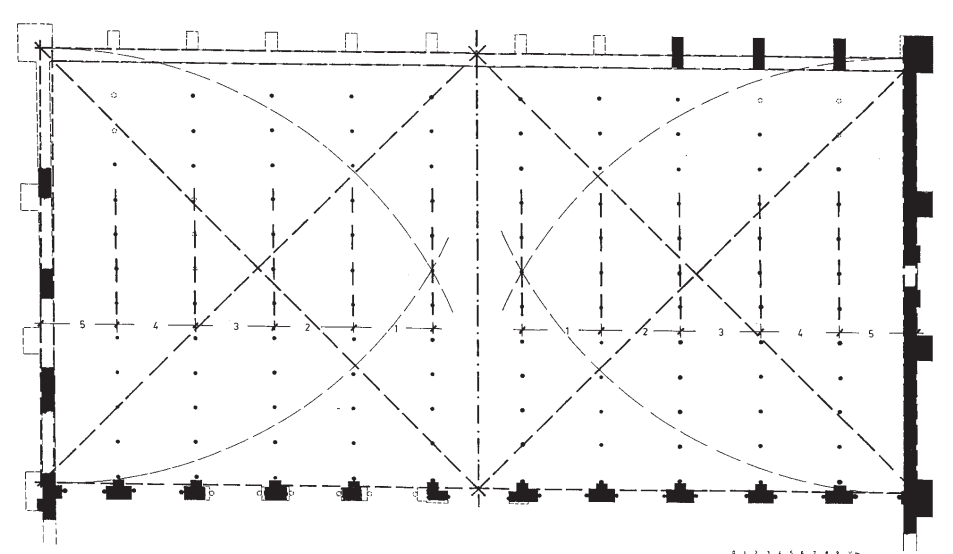

Fig. 6

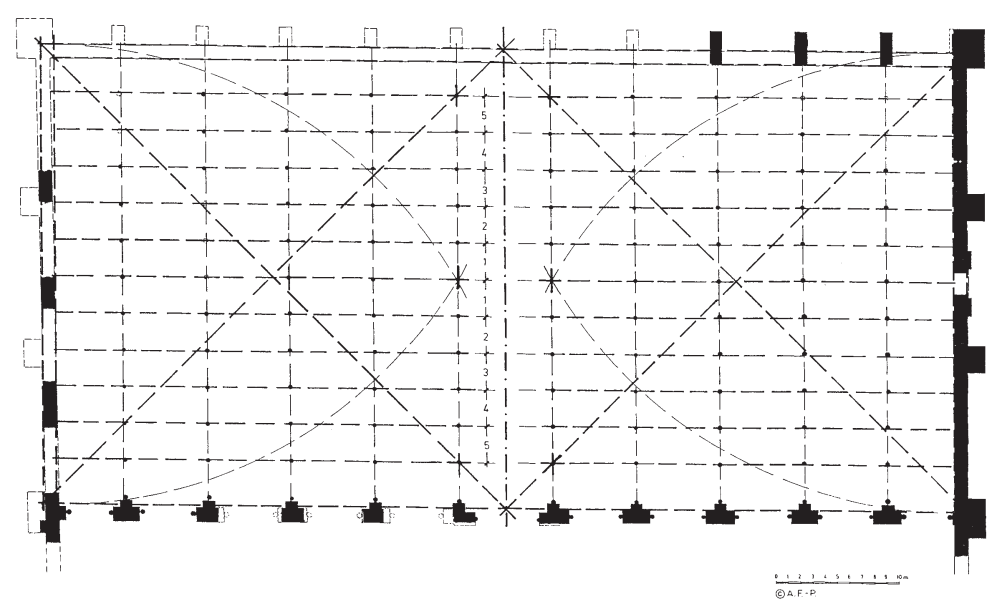

Fig. 7

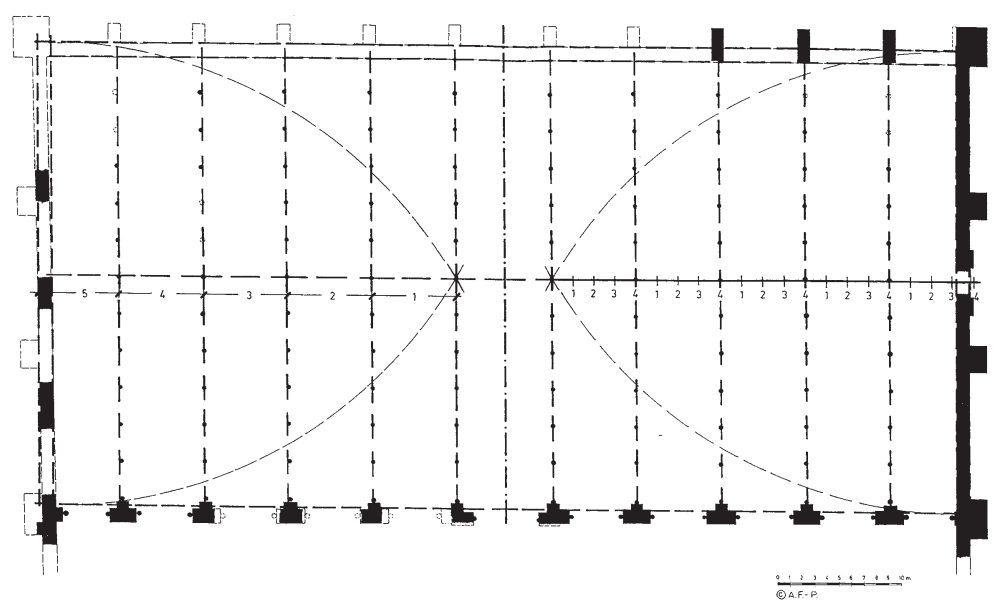

Fig. 8 


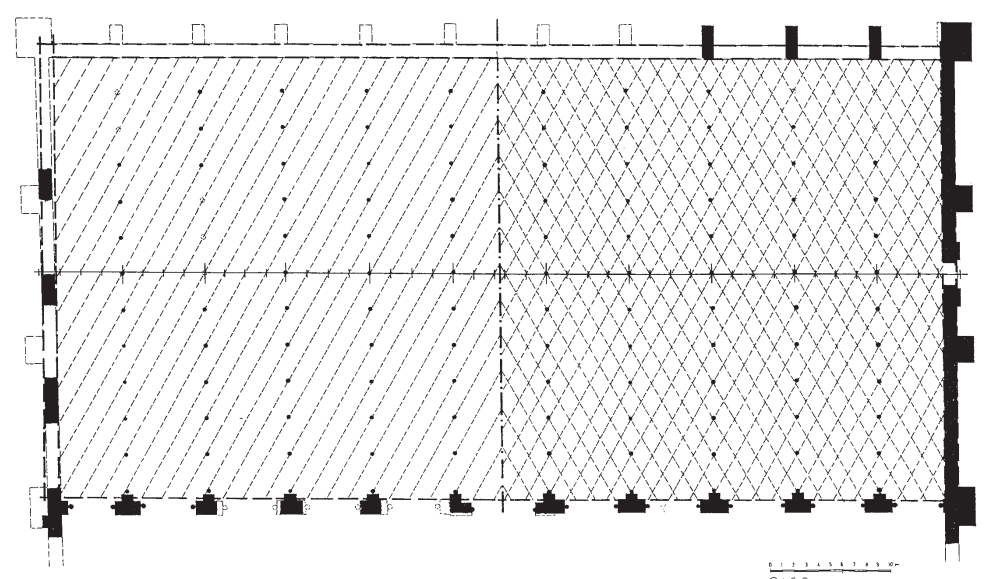

Fig. 9

\section{Trazado proporcional de la elevación de las arquerías}

Se resume de modo breve aquí para que se aprecie la perfecta relación proporcional entre la planta y la elevación de las arquerías. Todo es un proceso continuo desde la planta general de la mezquita hasta la altura de las armaduras decorativas de las naves. Es una perfecta articulación entre las partes y el todo y viceversa. Ya se ha tratado este punto con todo detalle ${ }^{7}$ sobre un dibujo efectuado por F. Hernández Giménez para la obra de Creswell ${ }^{8}$ (láms. I-III). Para empezar, el proceso de edificación fue el siguiente:

1) Lo primero que construyó el alarife fue el muro perimetral con sus contrafuertes, la arquería que separa el oratorio del patio, y las puertas de acceso (fig. 9).

2) Después de esto edificó las arquerías primera y décima, cogiendo el material de sus columnas (basas, fustes, capiteles y cimacios) de la preselección hecha en el patio. Para que igualaran todos los arcos de entibo de herradura, así como los pilares de sección rectangular que ensanchan las arquerías hacia las naves, el arquitecto mandó colocar las piezas cruciformes de modillones con diverso número de rollos y de distinta altura (fig. 10).

3) Obtenida una misma línea horizontal de arranques, empezó a elevar los pilares rectangulares a eje con las columnas y volteó, sobre cimbras de madera, los arcos de herradura de arriostramiento que quedan exentos por completo en su trasdós (fig. 11).

4) Sobre estos arcos de herradura se colocó una segunda

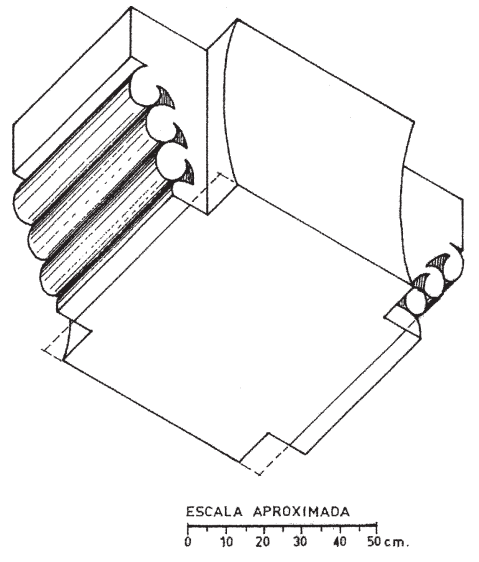

Fig. 10 cimbra y desde los pilares, ensanchados por un plano abiselado

\footnotetext{
7 A. FERnÁNDEZ-Puertas, "Las arquerías de las naves", pp. 25-41, especialmente pp. 33-35, figs. 5-8.

8 K. A. C. Creswell, Early Muslim Architecture, Part Two. Early 'Abbāsids, Umayyads of Cordova, Aghlabids, Tuülūnids, and Samānids. A.D. 751-905, with contributions by Félix Hernández, Georges Marçais, 'Abd al-Fattāh Hiilmī and Ḥasan 'Abd al-Wahhāẹ, Oxford at the Clarendon Press, 1940, p. 149, fig. 144.
} 
oblicuo, se volteó el segundo arco, de medio punto y estructural, por encima del cual se halla el muro que alberga la canal de desagüe en cada una de las arquerías (figs. 11-14, alzado y sección).

5) Con objeto de tener mayor soporte en su elevación, se empezó a construir desde las arquerías de las naves extremas, 1 y 11, hacia la central, la 6, de modo que apoyaban la 1 y 10 en los muros perimetrales, la 2 y 9 pudieron ayudarse en las arquerías construidas, y así hasta la nave axial.

6) Tras colocar la armadura plana decorativa con pares y cobijas en el momento de la elevación (figs. 11-14), se ultimó la obra al cubrir las naves con armaduras a dos aguas, de par e hilera con cartabones verticales en sus extremos N. y S.

7) Hecho esto, se quitaron todas las cimbras y apuntalamientos utilizados y dejaron diáfanas las arquerías con su doble elevación.
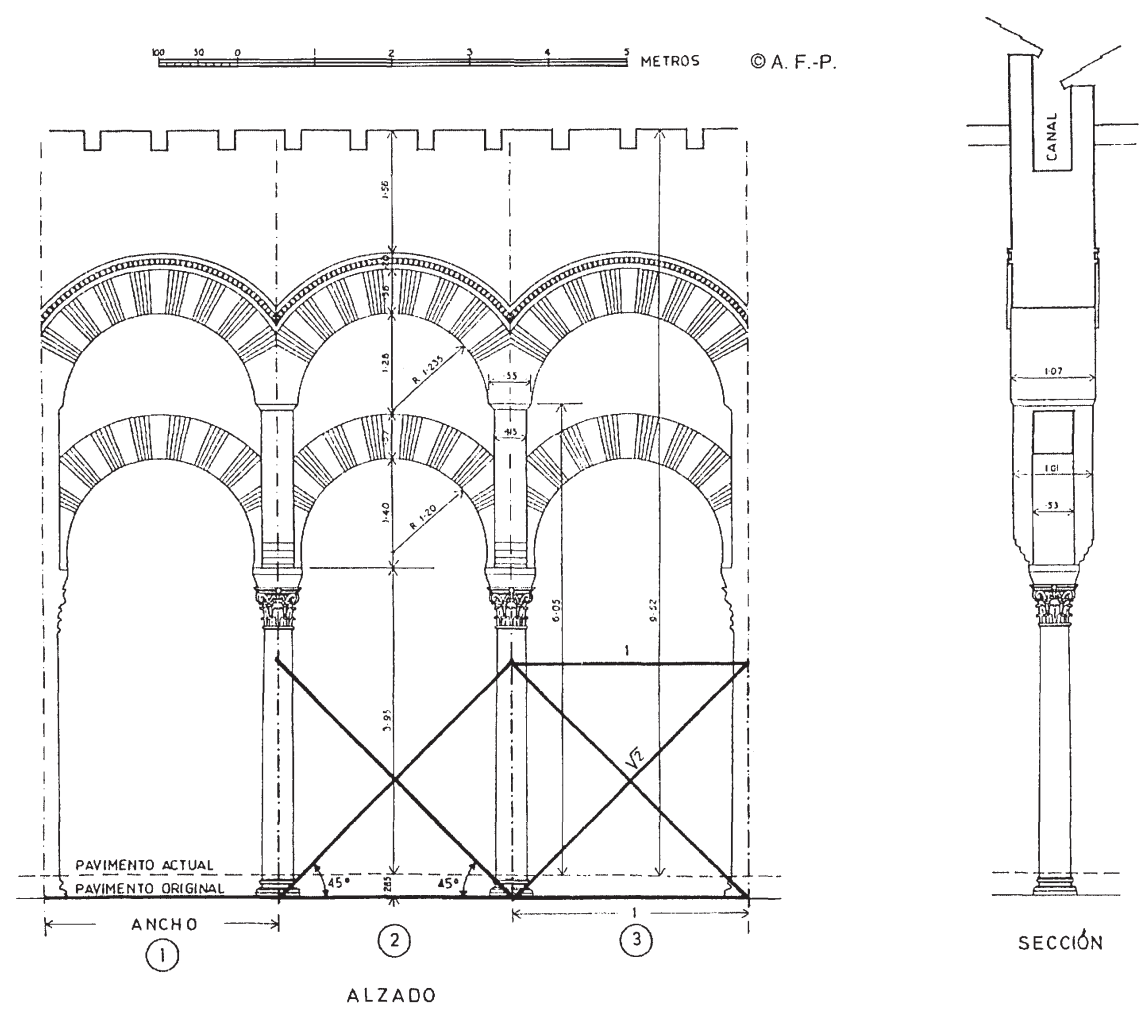

Fig. 11

Éste es el proceso de construcción, una vez establecido el lugar exacto proporcional en la planta, de los ejes de las columnas. Su elevación corresponde al mismo sistema proporcional ${ }^{9}$. Se resume aquí seguidamente este último, ya publicado, por ser esta Revista de mucho mayor alcance y trascendencia que donde lo di a conocer en el año 2000 (láms. I-III) $^{10}$.

9 Ya ha sido estudiado en "Las arquerías de las naves", pp. 34, 35, figs. 5-8.

${ }^{10}$ A. Fernández-Puertas, "Las arquerías de las naves", en Actas del XIII Congreso. 

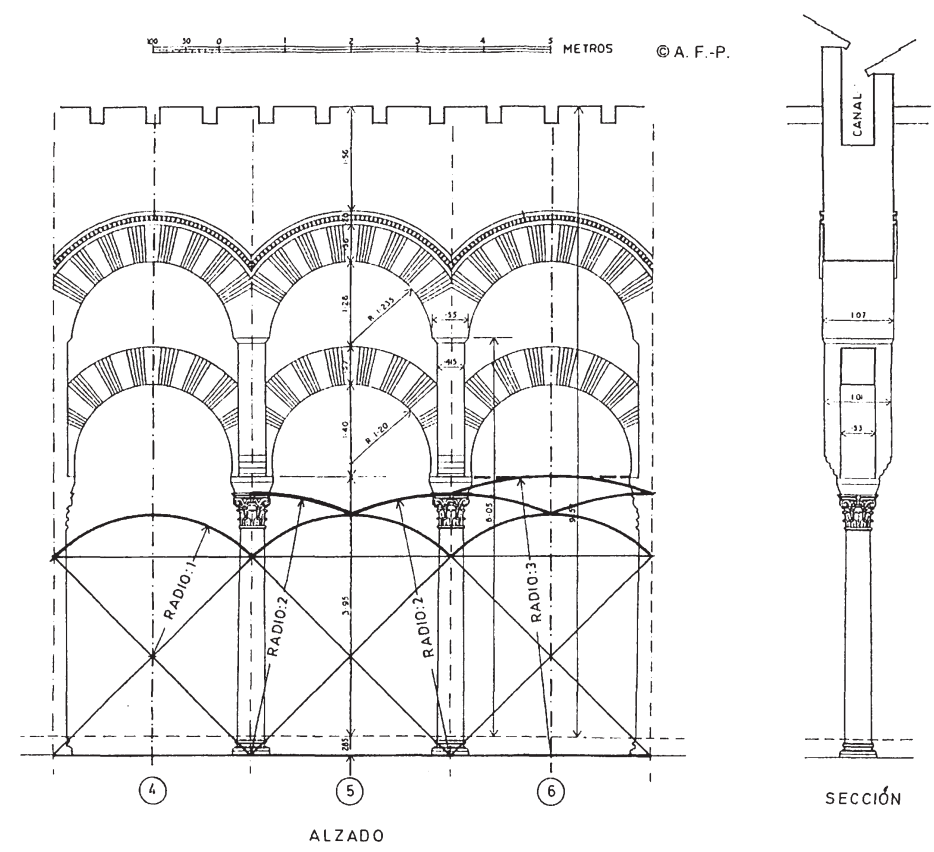

Fig. 12
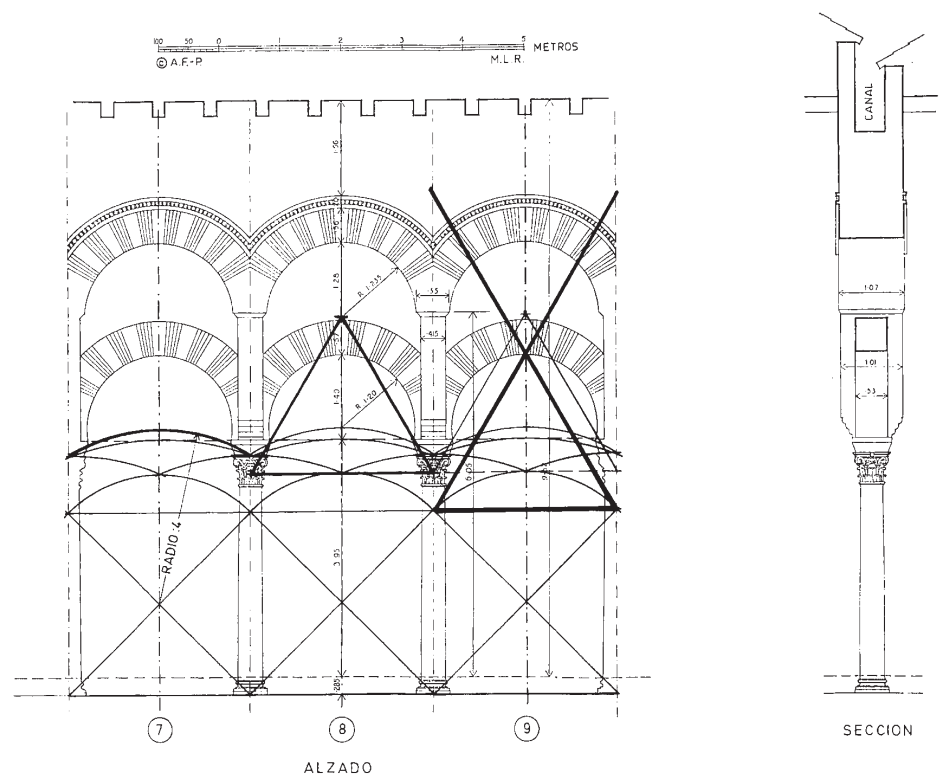

Fig. 13

AEA, LXXXI, 324, OCTUBRE-DICIEMBRE 2008, 333-356, ISSN: 0004-0428 


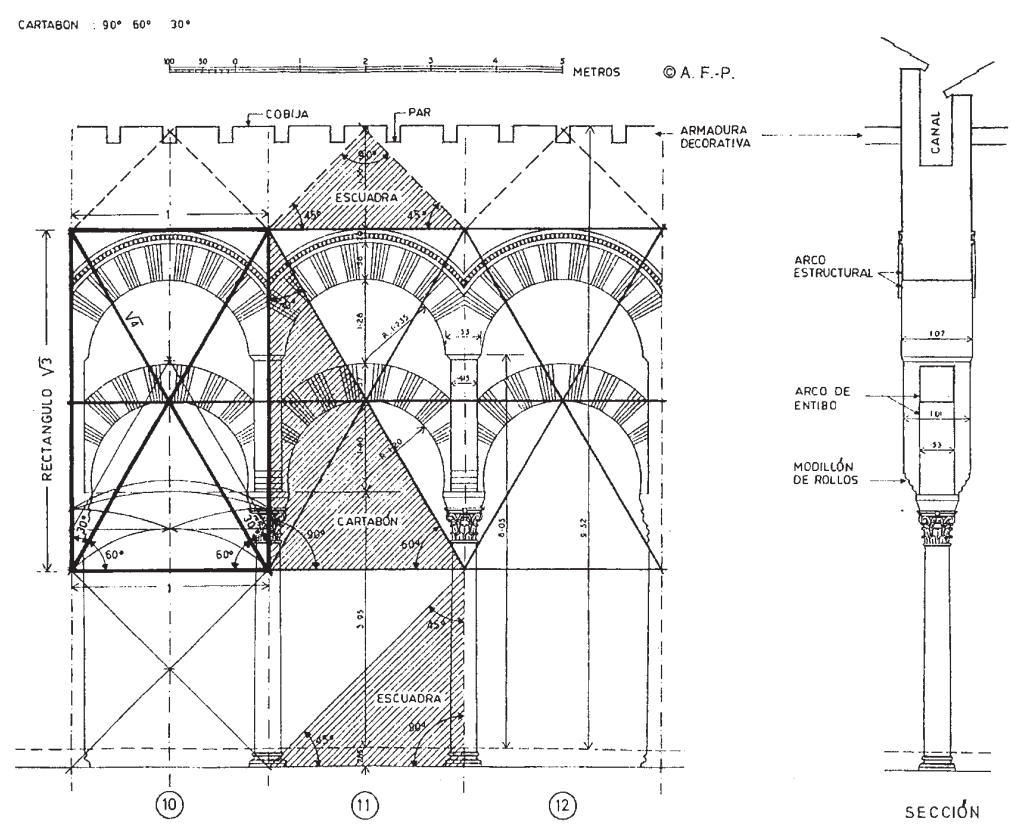

Fig. 14

1) El alarife tomó el ancho de eje a eje de las columnas como la unidad o lado de un cuadrado que construyó, fuera cual fuera el grosor de los fustes; luego le trazó sus diagonales (fig. 11: 1-3).

2) A continuación tomó una semidiagonal superior como radio:1 y trazó un arco de círculo (fig. 12: 4).

3) Seguidamente, adoptó un radio:2 desde el eje base del centro de las columnas al punto medio de dicho arco de círculo, y al abatirlo en vertical le dio la altura del capitel (fig. 12: 5). Es posible que esta medida varíe si el capitel es más o menos alto.

4) Para obtener la línea de impostas y el peralte del arco de entibo de herradura, tomó el radio:3 (fig. 12: 6), cuya longitud estableció desde el eje medio del arco al centro de la parte alta del capitel, donde volvió a dibujar el alarife un nuevo arco de círculo que le dio el peralte del arco de herradura tras prolongar su parte cimera en horizontal (fig. 12: 6).

5) Halló el centro del arco de herradura y la longitud del radio del mismo al tomar la distancia desde el centro del cuadrado base al punto axial superior del capitel, y trazar otro arco de círculo con un radio:4 (fig. 13: 7).

Hasta aquí el alarife hizo el trazado proporcional con la escuadra y el compás, sobre el cuadrado de la base.

6) Obtuvo el trasdós del arco de herradura (que da su grosor de ladrillo y medio), al dibujar, mediante cartabón, un triángulo equilátero cuya base asentó sobre el arco de círculo trazado por el radio:1 (fig. 12: 4, y fig. 13: 8).

7) Halló la línea del intradós del arco de herradura al situar un triángulo equilátero encima del cuadrado base y con igual longitud de lado (fig. 13: 9). 
8) Para obtener el arco de medio punto superior, con su rosca de ladrillo, invirtió este triángulo equilátero por su vértice hacia arriba (fig. 13: 9). Así obtuvo un rectángulo $\sqrt{3}$, cuya diagonal $(\sqrt{4})$ compone un cartabón (fig. 14: 10, 11).

9) Para obtener la altura de la armadura plana decorativa de madera, partió de las líneas ejes de las columnas y de los pilares, y, a la altura de este rectángulo, dibujó con la escuadra ángulos de $45^{\circ}$, que cuando se unen en el de $90^{\circ}$ forman una escuadra a escala proporcional menor, lo que da la altura deseada (fig. 14: 11, 12).

Luego, con escuadra, cartabón y escuadra reducida a escala menor, construyó el alarife toda la elevación, desde el suelo hasta la armadura plana de madera (fig. 14: 11; láms. I-III), y utilizó el compás para hallar el nivel de los capiteles y otros centros.

Como se ve, el genial alarife de 'Abd al-Raḥmān I, al construir la mezquita del siglo VIII, siguió en todo momento el mismo sistema proporcional: planta general, elevación de la Bāb alUzarā' y su ornamentación, planta del patio y del oratorio, y la elevación de sus arquerías desde el suelo hasta sus armaduras planas.

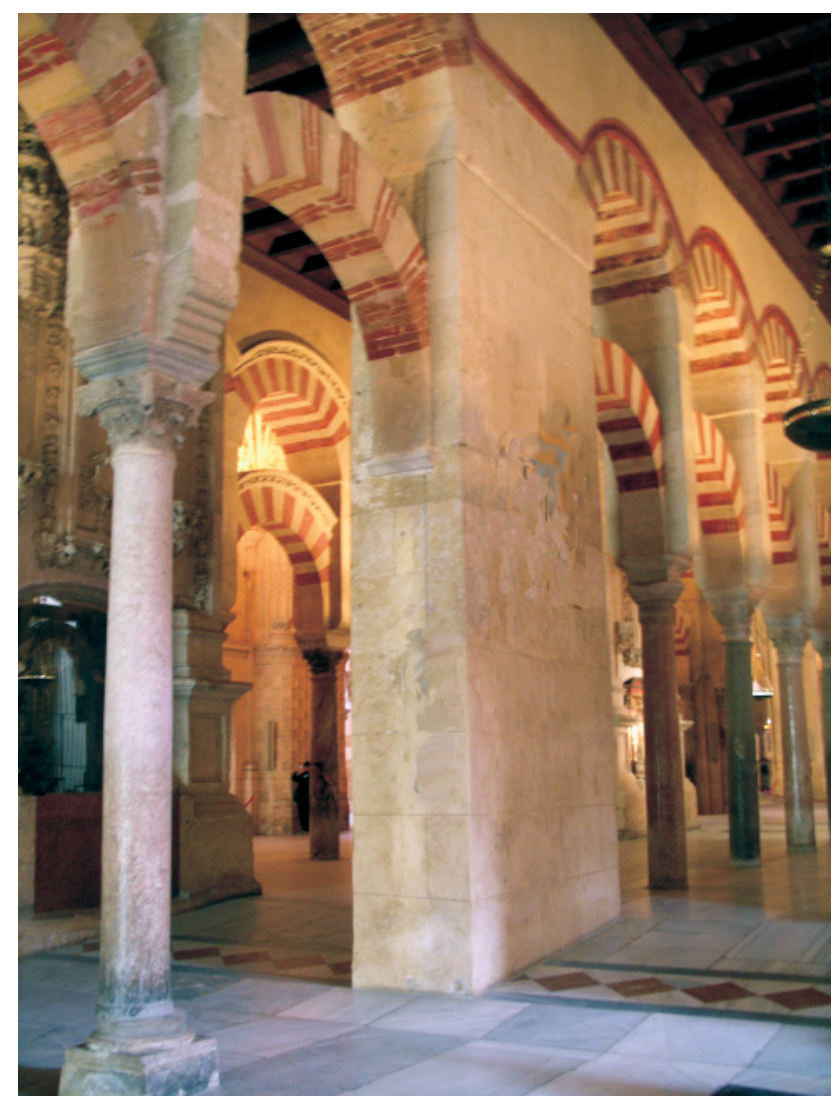

Lám. III. Contrafuerte de la mezquita de 'Abd al-Raḥmān I. El muro de la qibla demolido está señalado en la solería (Foto P. Marinetto Sánchez). 


\section{La qibla y el miḥrāb de la mezquita del siglo VIII}

Cuando el príncipe omeya 'Abd al-Raḥmān I llegó a al-Andalus, se proclamó emir independiente del nuevo califato 'abbāsí. Comprendió que tenía que establecer su poder no sólo de manera militar sino de modo aparente ante la población y, por esto, emprendió la construcción de la mezquita de Córdoba con un fin religioso y político. La orientó hacia el S. y no hacia SE. donde se halla la Meca desde la Península Ibérica. ¿Siguió en esto la tradición de las mezquitas y santuarios de sus antepasados omeyas en Siria y el Próximo Oriente y pretendió ignorar a la nueva dinastía 'abbāsí? ¿Se desconocía la situación geográfica de la Meca al situar la qibla al $\mathrm{S} . ?^{11} \mathrm{Me}$ inclino por la primera hipótesis más que por la segunda, dado el gran conocimiento geométrico y astronómico de la Antigüedad Clásica en al-Andalus, que se evidencia en el magnífico sistema de trazado proporcional de todos los elementos de la mezquita en planta y alzado relacionados entre sí.

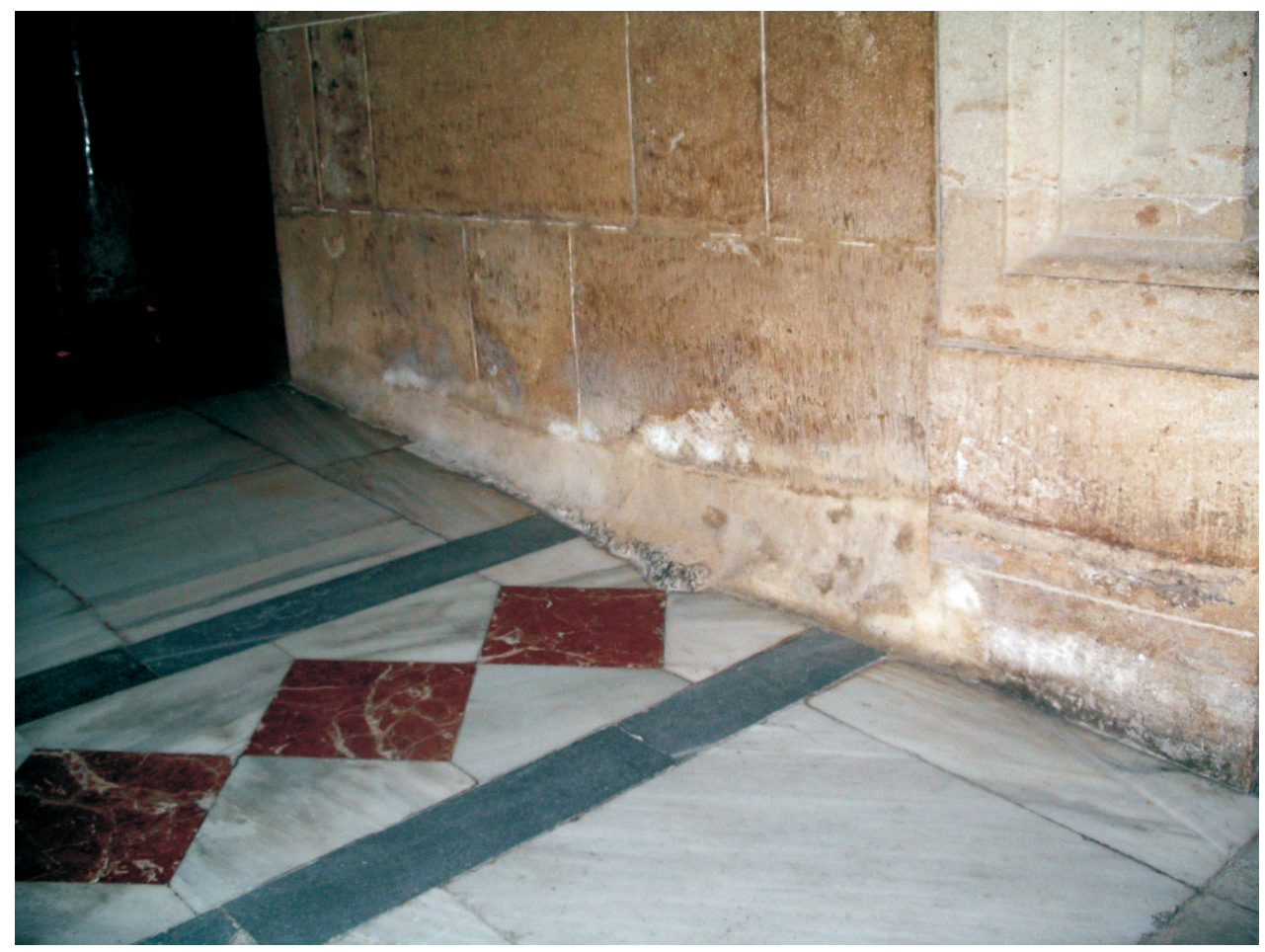

Lám. IV. Grosor del muro de la qibla demolida de 'Abd al-Raḥmān I: losas de mármol rojo y blanco y cenefas grises longitudinales (Foto P. Marinetto Sánchez).

${ }^{11}$ El vocablo qibla significa en origen "sur, mediodía”, de ahí que en las primitivas mezquitas de los cuatro califas rāšidūn (= ortodoxos o bien guiados) y las de los omeyas de Siria y Arabia que miraban a la Meca, el muro meridional hacia donde dirigían los creyentes la oración era el muro sur, y así pasó a denominarse el muro de la qibla, con un segundo significado, estuviera o no orientado a mediodía. 


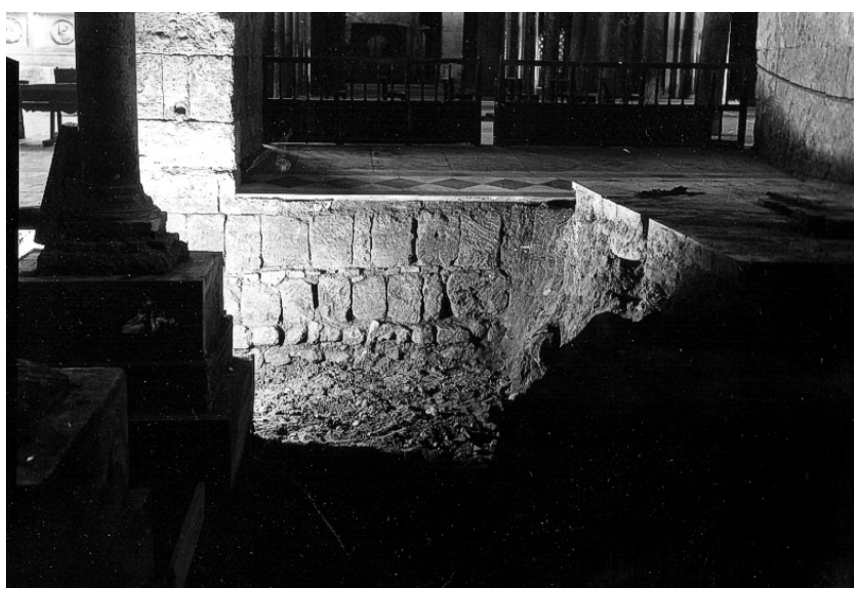

Lám. V. Muro de la qibla de 'Abd al-

Raḥmān I. Su cimentación y unión con el contrafuerte. A la izquierda, las columnas provistas de cimentación escalonada por F. Hernández Giménez (Foto F. Hernández Giménez).

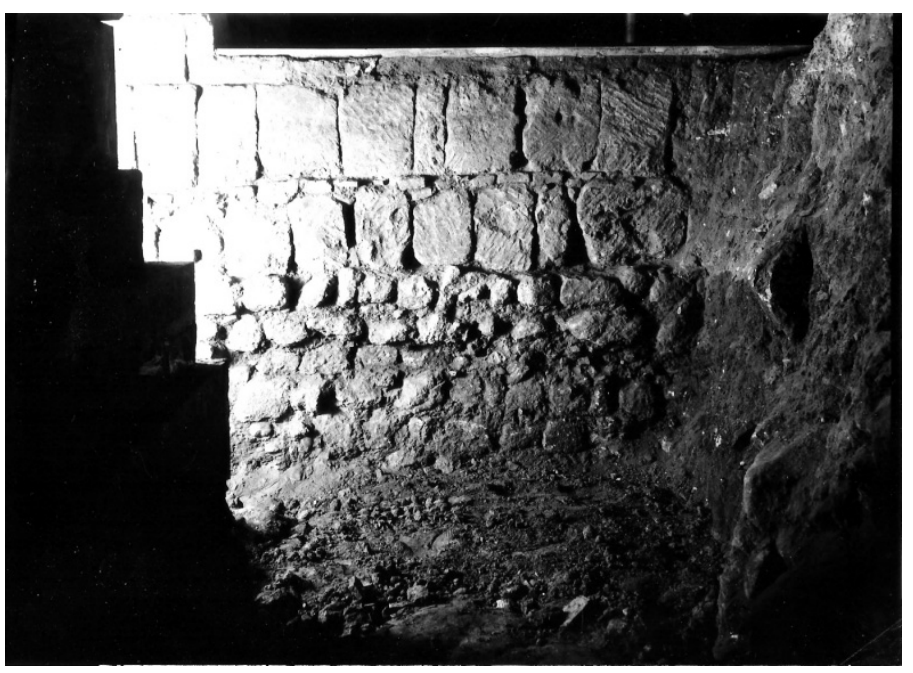

Lám VI. Muro de la qibla de 'Abd al-Raḥmān I. Su cimentación y unión con el contrafuerte. A la izquierda, las columnas provistas de cimentación escalonada por F. Hernández Giménez (Foto F. Hernández Giménez).
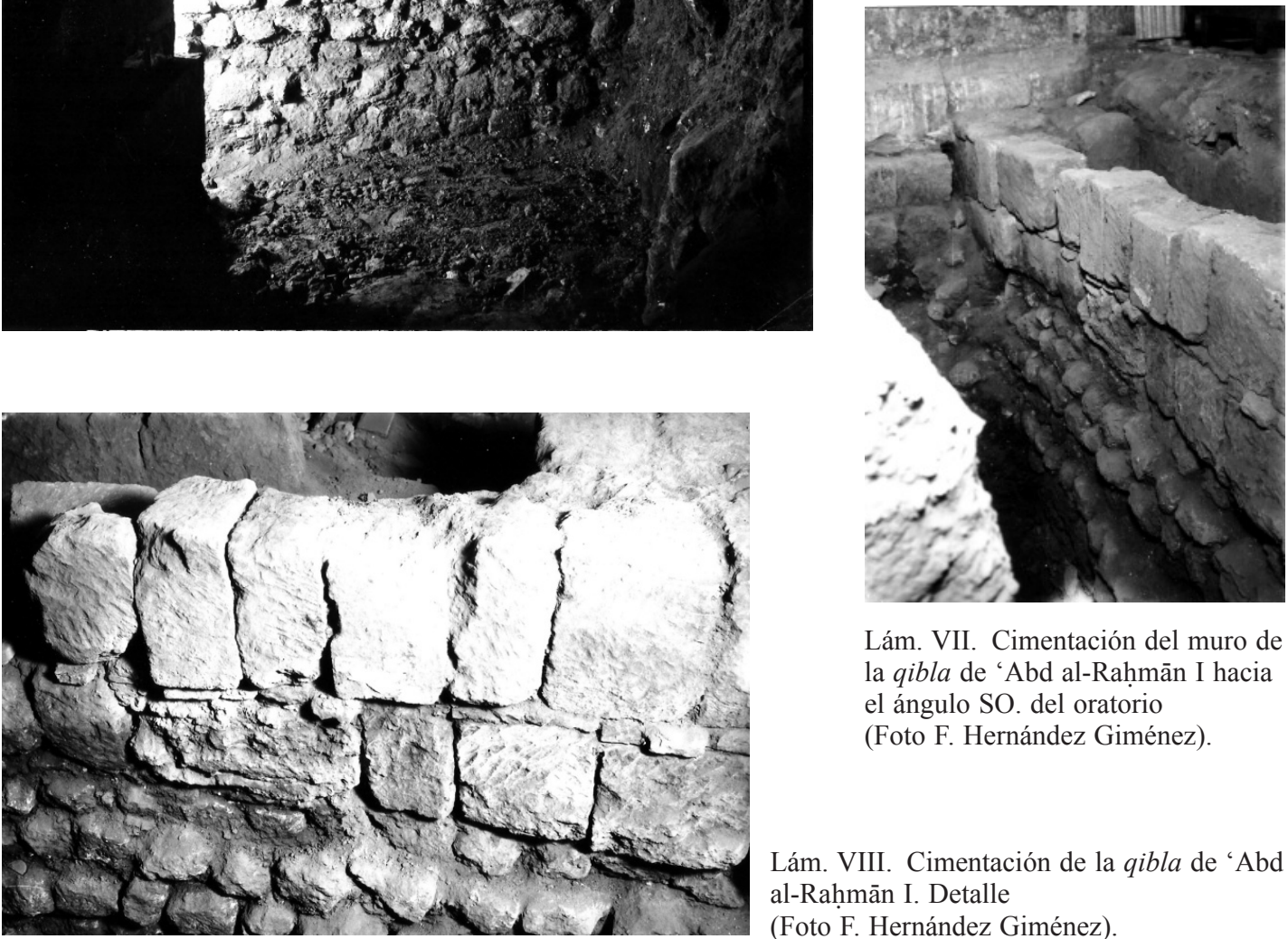

Lám. VII. Cimentación del muro de la qibla de 'Abd al-Rahmān I hacia el ángulo SO. del oratorio (Foto F. Hernández Giménez).

Lám. VIII. Cimentación de la qibla de 'Abd al-Raḥmān I. Detalle

(Foto F. Hernández Giménez).

AEA, LXXXI, 324, OCTUBRE-DICIEMBRE 2008, 333-356, ISSN: 0004-0428 


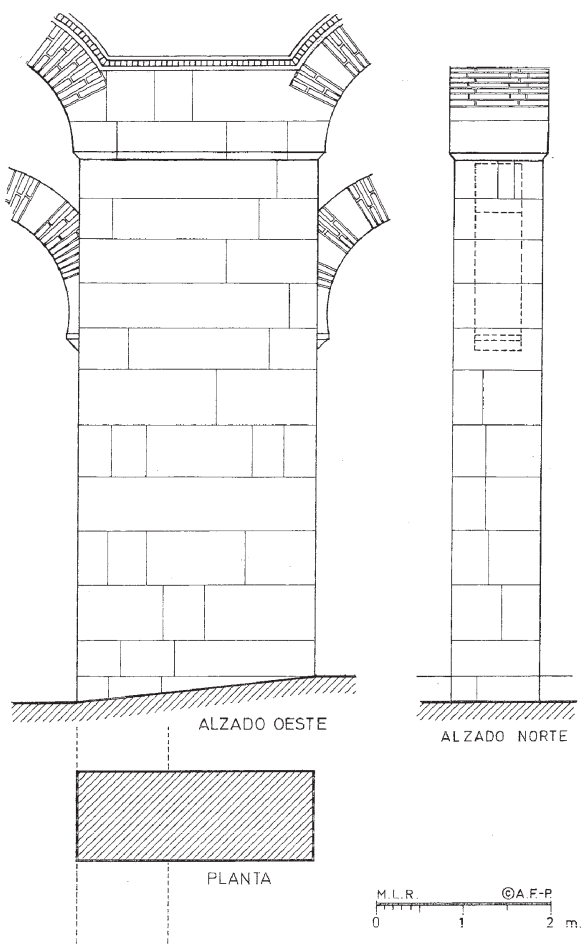

Fig. 15

Cuando 'Abd al-Raḥmān II prolongó el santuario hacia S. en el siglo IX, dotó a las nuevas arquerías de su ampliación de una buena cimentación compuesta de muros corridos longitudinales sobre sillares labrados trabados, suprimiendo los plintos y las basas reutilizados que había en el oratorio del siglo VIII (láms. I-III, a la derecha del contrafuerte). Se demolió el muro de la qibla del siglo VIII sólo hasta la rasante del suelo en los tramos correspondientes al ancho de las once naves, pero, por seguridad, no se tocaron los contrafuertes $(=a r \hat{y} u l)$ rectangulares de las diez arquerías del siglo VIII que sobresalían del muro de la qibla (figs. 1-3, 15; láms. III-VI). Éste corre de modo ininterrumpido, con sus sillares bien trabados, la amplitud de las once naves y acaba en los contrafuertes angulares SE. y SO. (láms. III-VIII). El hecho de que el muro de la qibla corriera entre ambos contrafuertes, es una de las varias pruebas irrefutables de que la mezquita del siglo VIII tuvo once naves, contra lo que dicen los textos árabes de Aḥmad al-Rāzī y de Ibn al-Naz̧āam recogidos por Ibn Ḥayyān en su obra Muqtabis III-12 ${ }^{12}$ (lám. VII).

Las fotografías hechas por F. Hernández Giménez muestran la base del muro de la qibla desmontada en el ancho de varias naves del lado $\mathrm{O}$. del oratorio, indicado en las láminas III a la VI por la mencionada solería de losas de color rojo colocadas en diagonal (láms. VII, VIII) hasta que entestan con el contrafuerte del lado O. del oratorio. Se ve la trabazón perfecta con uno de los contrafuertes rectangulares (láms. IV-VI). Se observa que sobre el terreno recrecido por la estratigrafía de canto rodado con algo de argamasa se asentaron dos filas de piedras irregulares para que sirvieran de base a la primera hilera de sillares a hueso colocados a tizón, es decir, por los frentes extremos de los bloques, como también se ve en el muro de la qibla que continúa hasta el ángulo SO. por debajo de la nave extrema de poniente (láms. V-VIII). Por encima hay algunos cantos y fragmentos que nivelan el asiento de la segunda hilera de sillares, a hueso y dispuestos por sus cabezas de medidas desiguales. La tercera hilera tenía su cantería colocada ya a soga y tizón,

12 Ben Haián de CóRdoba (m. 469 H./1076 J.C.). Muqtabis II. Anales de los Emires de Córdoba Alhaquém I (180-206 H./796-822 J.C.) y Abderramán II (206-232 / 822-847). Edición facsímil de un manuscrito árabe de la Real Academia de la Historia (Legado Emilio García Gómez) al cuidado de Joaquín Vallvé Bermejo, Madrid 1999, folio 141r, p. 107, línea 9 en adelante. Ibn ḤAYYān, Crónica de los emires Alhakam I y 'Abdarrậmān II entre los años 796 y 847 [Almuqtabis II-1]. Traducción, notas e índices de Mạmūd 'Alī Makkī y Federico Corriente, Instituto de Estudios Islámicos y del Oriente Próximo. La Aljafería, Zaragoza, 2001. Ms folio 141r, trad. p. 173, nota 301. Texto árabe por Maḥmūd 'Alī Makkī, por el Markaz al-malik Fayșal li-l-buhūṭ wa-l-dirāsāt al-islāmiya, 1424/2003, pp. $284,285$. A ambos autores debo la cortesía que me hayan suministrado en pruebas de imprenta la edición del texto árabe. Como trato en otro lugar, este manuscrito árabe muestra el error de decir que la mezquita del siglo VIII era de nueve naves y que en el siglo IX se amplió lateralmente. Han seguido esta insostenible teoría Lévi Provençal y É. Lambert. Pero ni M. Gómez-Moreno, ni F. Hernández Giménez, ni L. Torres Balbás, ni yo mismo entre otros, podemos admitir esta noticia errada ante la evidencia arquitectónico-arqueológica del propio monumento. A. FERNÁNDEZ-PUERTAS, "I. Mezquita de Córdoba", p. 226, nota 25. Volveré sobre este punto con toda la extensión debida en "La ampliación de la mezquita de Córdoba entre 833 y 848 por 'Abd al-Rahmān II. Ultimación por Muhammad I”. 
como muestra el sillar con su cara longitudinal, parte del cual se ha conservado en toda su altura en el contrafuerte y rebajado por debajo del pavimento de mármol con que soló F. Hernández Giménez el grueso del muro de la qibla (fig. 15; láms. III-VI).

Al rebajar F. Hernández Giménez el suelo de la mezquita de 'Abd al-Raḥmān I al nivel que tuvo en el siglo VIII, quedaron expuestos unos centímetros de la parte baja de un sillar común al contrafuerte y al muro desmochado de la qibla que cerraba la nave (lám. IV). F. Hernández Giménez dejó recortadas las losas blancas pentagonales de la banda de mármol de colores gris, blanco y rojo que señala el grosor que tiene el muro soterrado de la qibla. Este testigo arqueológico a la vista indica cómo cerraba a S. el santuario con un muro corrido hacia el interior, mientras que los contrafuertes sobresalían hacia el exterior (figs. 1-3, 15; láms. III-VI) $)^{13}$.

¿Cómo y en qué momento procedió 'Abd al-Rahmān II a demoler el muro de la qibla de la mequita original al ampliar el santuario en el siglo IX? Por sentido común el emir realizó su obra de agrandamiento desde el exterior de la mezquita para no estorbar o interrumpir el uso de la sala de oraciones durante el tiempo de su construcción. Cuando la ampliación estuvo prácticamente acabada se inició el desmonte del muro de la primitiva qibla. El último tramo que se derribó fue el de la nave central con el nicho del mi hrāb labrado en el grosor de la cantería del muro (fig. 16; lám. XI).

Se construyeron primero los muros perimetrales laterales de la ampliación del siglo IX hacia el S. y los de cimentación longitudinales de las nuevas arquerías; luego se rellenaron con tierra y piedras sueltas los espacios huecos delimitados por los muros de cimentación que iban a sostener las arquerías; el relleno después se apisonaba hasta dar un firme seguro al suelo de la ampliación del oratorio (lám. III, a la derecha del contrafuerte). Por último, se construyó como cierre, desde los dos contrafuertes extremos a E. y O., el muro de la segunda qibla emiral. Se finalizó la ampliación al construir el muro de la qibla de 'Abd al-Raḥmān II con sus contrafuertes. Se dotó al oratorio ampliado de una nueva puerta en el lado E., para la cual, debido al declive del terreno hacia el río a mediodía, se construyó una escalera de doble subida -o sea, con peldaños por su lado N. y S.-, para acceder desde la calle de naciente que quedaba a unos $3 \mathrm{~m}$. por debajo del suelo del oratorio (figs. 2, 17; láms. IX, X).

\section{El miḥrāb de la mezquita de 'Abd al-Raḥmān I}

Cuando en 1932 F. Hernández Giménez excavó el lado E. del oratorio emiral de los siglos VIII y IX, halló una puerta al santuario practicada en el tramo central de los cinco (láms. IX, X). Encontró en esta excavación cinco fragmentos decorativos que estaban fuera del muro perimetral, en el área de la calle (figs. 16, 18-20; lám. XI). Había un sexto fragmento cuando yo visité la excavación con mi mujer en 1989; hice que el vigilante Carlos Soriano, que nos acompañó, se lo entregara al canónigo correspondiente (fig. 21). Estos fragmentos llevaron a pensar a F. Hernández Giménez que eran restos de la decoración de la fachada de esta puerta del siglo IX que mandó demoler Almanzor cuando hizo su ampliación (377/987-988).

${ }_{13}$ En 1997-1998 el personal de un arquitecto que trabajaba con un proyecto en la mezquita e ignoraba lo que era aquel resto arqueológico, optó por que se picase la parte saliente del sillar y se completara la losa poligonal blanca de mármol. Por fortuna el arqueólogo Pedro Marfil Ruiz que realizaba otra tarea en el monumento, pudo evitar la destrucción total de este testimonio histórico-arqueológico perteneciente al resto del muro que entestaba con uno de los contrafuertes de la qibla del siglo VIII (láms. III-VI). 


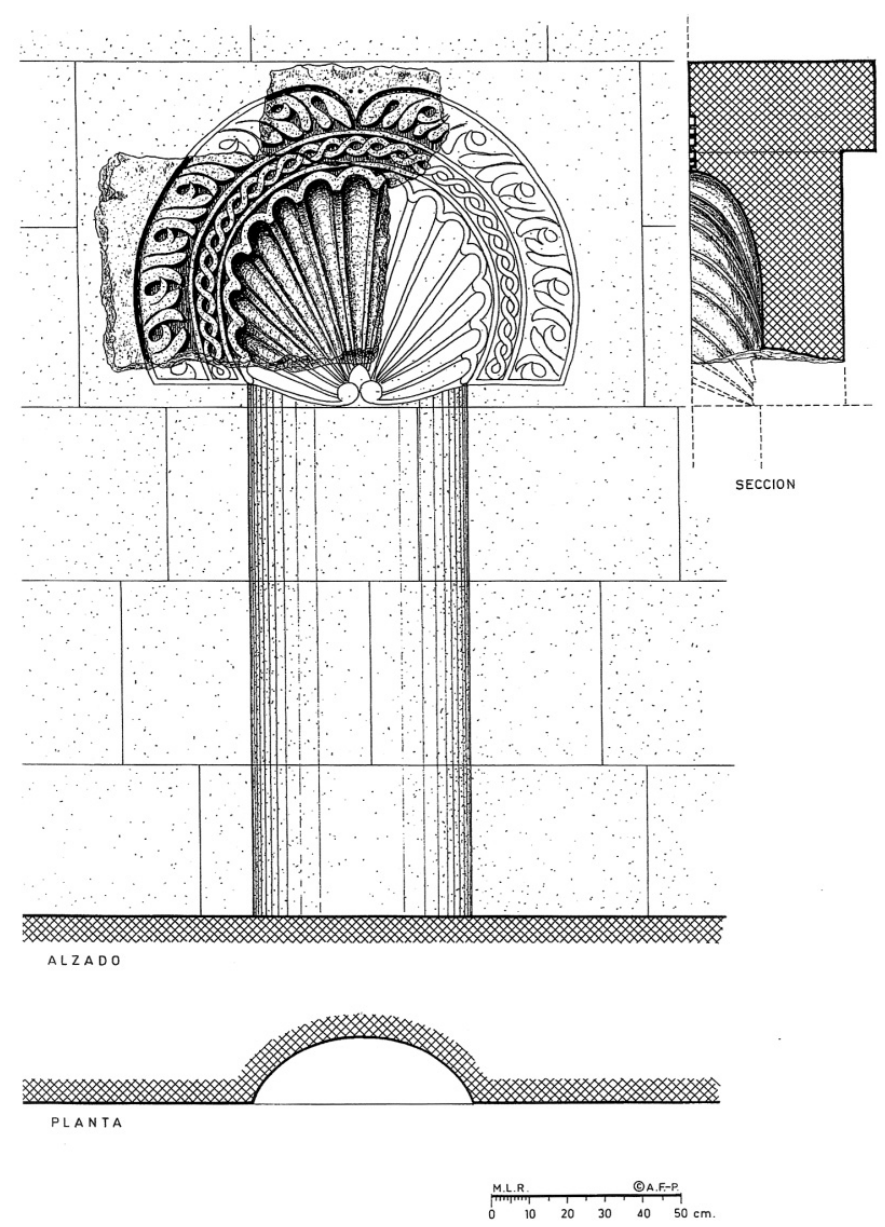

Fig. 16

L. Torres Balbás siguió esta opinión. Por el contrario, yo estimo que por su estilo y técnica de labra modelada y sin aristas hay que clasificar estos fragmentos como del siglo VIII. Son muy distintos a lo que se conoce del siglo IX al compararlos con el dovelaje abiselado a dos planos, claro y oscuro, del arco de herradura de la Bāb al-Uzarā', o, en general, a todos los capiteles tallados del siglo IX. Esta fachada fue restaurada en época de Muhammad I, como especifica la inscripción cúfica de su tímpano, la cual atestigua la intervención de dicho emir al consolidar esta fachada en el 241/855-856 mediante su fatà Masrūr. La labra de la decoración de los capiteles del siglo IX difiere por completo de la de estos fragmentos.

En mi opinión, estos fragmentos decorativos no pudieron pertenecer a la fachada del siglo IX ni por su tipo de decoración ni por sus medidas. La puerta de la Bāb al-Uzarā’ tiene un hueco de entrada entre mochetas de $150 \mathrm{~cm}$., similar al de esta puerta de naciente del siglo IX (fig. 2). Si se considera las dos piezas del nicho agallonado fragmentado, de sólo 1,32 m. una vez restituida toda su amplitud, es imposible que pudiera ser el tímpano del vano de entrada de la puerta E., por ser de bastante menor dimensión que el hueco de esta puerta, ya que tendría que ser no sólo mayor que su hueco, sino también más que la amplitud de su dintel (fig. 16). 

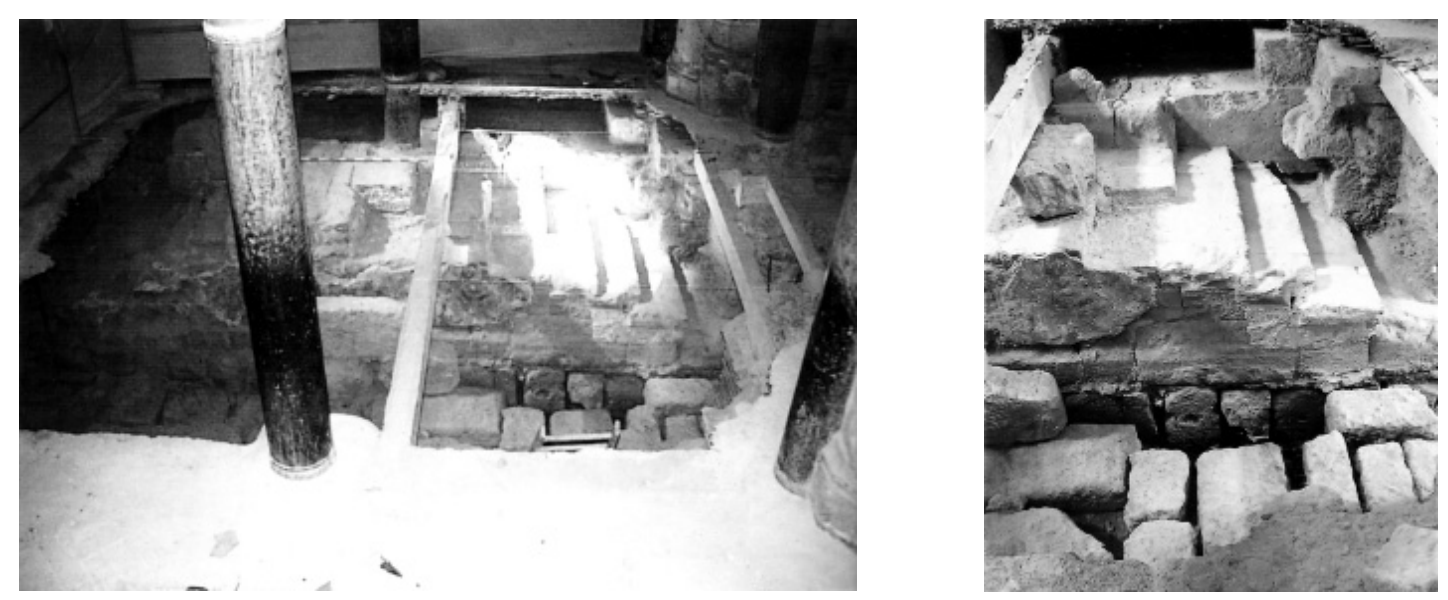

Lám. IX. Excavación de F. Hernández Giménez de la puerta de acceso E. hecha en el siglo IX (Foto P. Marfil Ruiz).

Lám. X. Detalle de la puerta y escaleras hechas en el siglo IX (Foto L. Estaban y M. Pijoan).

Si la fachada E. fue tripartita, se podría pensar que fuera el ornamento de un nicho lateral ciego. Pero a esto hay que indicar dos objeciones: 1) No se han encontrado fragmentos más que de una charnela, cuando se requieren dos, una para cada lado de la puerta. 2) Este esquema de venera agallonada como tímpano o decoración de nichos laterales, no se encuentra en ningunas de las fachadas de la mezquita, pues el modelo compositivo tripartito de sus puertas lo fijó la Bāb al-Uzarā' en el siglo VIII, como se ven en las fachadas de al-Hakam II y Almanzor. La Puerta de San Miguel -adonde desembocaba el puente de arcos del säbāt construido a fines del siglo IX por el emir 'Abd Allāh-, muestra su tímpano y composición análogo a lo establecido en la Bāb al-Uzarā', y fue decorada en época de al-Ḥakam II al demoler el califa el pasadizo alto de su bisabuelo.

Publiqué en 1979 una hipótesis de que dos de estos restos decorativos hallados por F. Hernández Giménez pertenecían al primer mịhrāb de la mezquita del siglo VIII de Córdoba. Al demoler el tramo central, el nicho de este mịhrāb se fragmentó por estar tallado en los sillares mismos -técnica que aparece en la decoración de la Bāb al-Uzarā'-y, con toda probabilidad, se enterraron en el siglo IX en torno al muro perimetral E. de la mezquita como relleno de su andén o bien reutilizados en el talud adosado al muro (figs. 2, 17). No puedo asegurar ni lo uno ni lo otro porque el tema nunca surgió en conversación con F. Hernández Giménez (figs. 16, 18-21; lám. XI). Lo que es indudable es que cuando al-Hakam II realizó su ampliación en el siglo $\mathrm{X}$ ensanchó el arrecife (al-rasif = la calle) en torno a la mezquita y todos estos fragmentos tenían que estar en el siglo $X$ reaprovechados en la obra de su andén ataludado (figs. 2, 17; lám. XII).

M. Gómez-Moreno, según los datos proporcionados por F. Hernández Giménez, escribió sobre estos fragmentos que:

"al reconocerse ahora el subsuelo de la mezquita en su extremo oriental, aparecieron cinco fragmentos de piedra caliza correspondientes a una decoración como nichos de poco fondo, en forma de arcos de herradura avenerados con guarnición de hojas, exactamente como las de la portada de San Esteban: su ancho, 1,32 m. [...] En Bagdad hay 


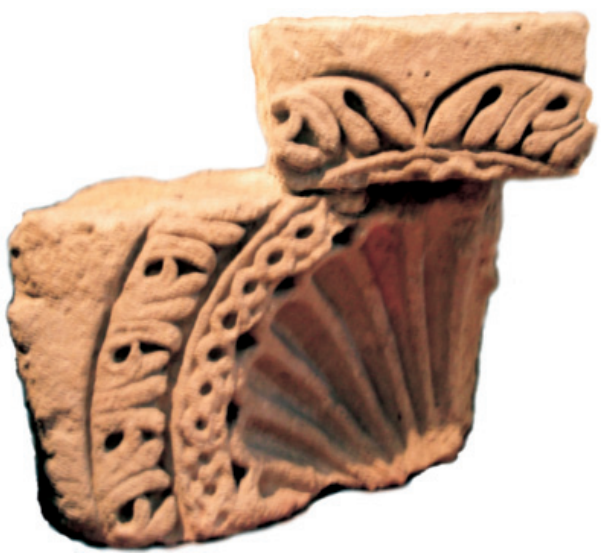

Lám. XI. Restos del mịhrāb de la mezquita de 'Abd al-Raḥmān I (Foto P. Marinetto Sánchez).

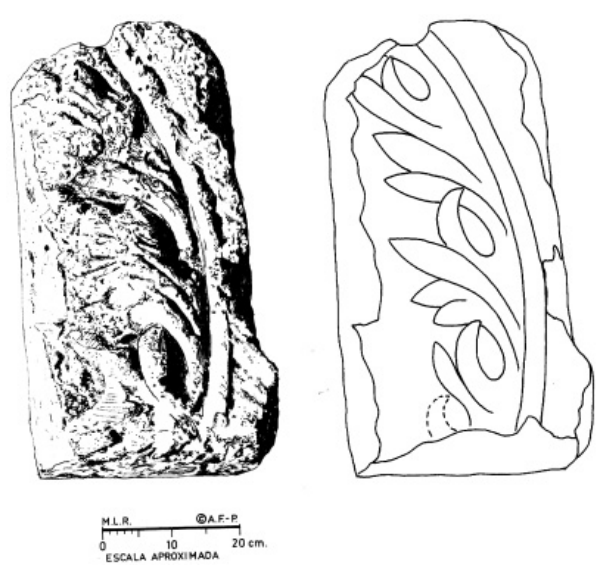

Fig. 18

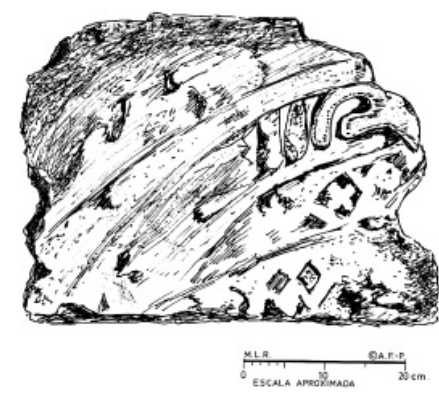

Fig. 19

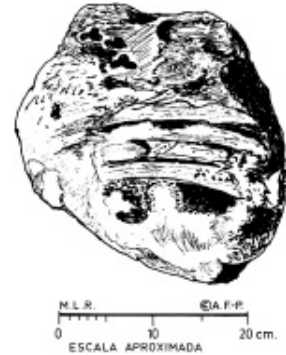

Fig. 20

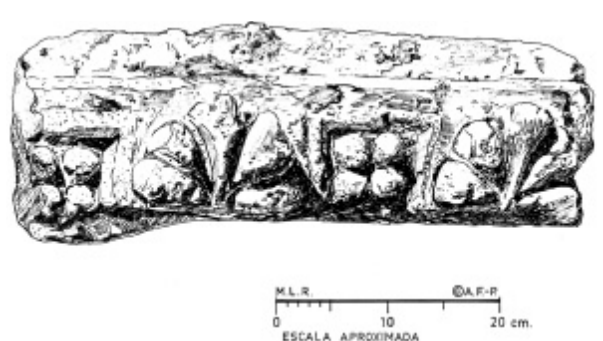

Fig. 21

otro, que se cree procedente de alguna iglesia y sirvió de mihrab en una mezquita: es de mármol; su tamaño como será éste de Córdoba, y su adorno de estilo siriaco, aún clásico; otros pequeñitos, por adorno, en maderas de la mezquita Alacsa de Jerusalén, atribuidas al 780, y en el mihrab de la de Cairuán, que data del siglo IX. Ahora bien, la mezquita primitiva de Córdoba no tuvo mihrāb saliente, como acredita su cimentación, caso repetido en otras orientales, como la Alacsa, la de Fustat y aun la de Damasco: sí es posible que le sustituyesen los tales arcos, pues eran dos a lo menos, y queda establecida, en definitiva, la hermandad entre éstos, la portada de San Esteban, los soportes de las arquerías a base de sus modillones y el almenado"14.

14 M. Gómez-Moreno, El arte árabe español, p. 42, fig. 39. 
L. Torres Balbás dice sobre el mịhrāb de la mezquita de "Abd al-Raḥmān I que "su planta debió de ser semicircular, a juzgar por los de otras contemporáneas. De su cimentación se deduce que no sobresalía del muro de la qibla" 15 . Informado por F. Hernández Giménez, estimó que los restos decorativos aparecidos en la excavación de la fachada E. pudieran ser de los siglos VIII o IX:

"unos fragmentos de nichos agallonados, de piedra caliza, poco fondo y 1,32 metros de ancho, cuyo arco de herradura rebordean, a modo de arquivoltas, dos fajas decoradas, respectivamente, con labor de trenzas y de hojas planas y lisas digitadas [...] Aparecieron en el subsuelo del extremo oriental de la mezquita y se conservan adosados a uno de sus pilares. Pudieron también labrarse estos fragmentos en el reinado del emir 'Abd al-Raḥmān II"16

Por el lugar del hallazgo -el subsuelo próximo a la puerta abierta por 'Abd al-Raḥmān II en el siglo IX-, F. Hernández Giménez pensó que eran restos decorativos de la misma, y por eso los montó adosados a los pilares de la catedral cristiana, con los otros restos, lo más próximo al lugar que tuvo la puerta abierta por 'Abd al-Rahmān II, donde han estado hasta 1997-199817. Pedro Marfil Ruiz, en su reciente publicación de la excavación de la fachada E. hecha por F. Hernández Giménez, escribe: "la aparición de restos de decoración arquitectónica emiral, perteneciente posiblemente a la puerta existente en la antigua fachada [del siglo IX]"18.

En 1979 seguí la opinión expuesta por M. Gómez-Moreno, y estimé que los dos fragmentos de la charnela aparecidos en la excavación tuvieron que ser del nicho del miḥrāb tallado de 'Abd al-Raḥmān I (fig. 16; lám. XI) ${ }^{19}$. El fragmento de nicho agallonado tiene sus orígenes en la arquitectura romana y paleocristiana, y se halla desarrollado ya en la arquitectura visigoda; pasó como en la omeya oriental y proto-'abbāsíi ${ }^{20}$ en tableros de madera de la mezquita de al-Aqsà, en los nichos y decoración pictórico-arquitectónica del palacio de Jirbat al-Mafŷār, y en el mihrāab 'abbāsí de la mezquita de al-Jașșakí de Bagdad ${ }^{21}$, fechado hacia el 766 y que posiblemente fue el nicho de la mezquita 'abbāsí de al-Mansūrr22.

Dos cenefas decoran el nicho agallonado que apareció en la excavación de 1932 (fig. 16; lám. XI). La interior está decorada por dos cintas entrelazadas que componen nudos ${ }^{23} \mathrm{y}$ la exterior ornamentada con sendas ristras de acanto enfrentadas y separadas en la clave. Cada hoja de acanto tiene tres o cuatro foliolos, el primero de los cuales se curva y llega a pisar el inmediato superior, que ofrece explayamiento descendente, por lo que se origina entre ambos foliolos un vano ovalado; las dos hojas inmediatas a la clave tienen más grande el limbo de sus foliolos. Esta

15 L. Torres Balbás, Arte hispanomusulmán, p. 351, nota 34.

16 L. Torres BalBás, Arte hispanomusulmán, p. 358, fig. 163.

${ }^{17} \mathrm{Al}$ efectuar el levantamiento del suelo para que Pedro Marfil Ruiz limpiara la excavación y tomara sus datos, el arquitecto del proyecto desmontó el fragmento del nicho agallonado y luego el Cabildo lo ha colocado sobre el suelo, en una vitrina anexa al área SE. del Sagrario, recientemente hecha museo en la ampliación de Almanzor.

18 Pedro MarfiL Ruiz, "Avance de resultados del estudio arqueológico de la fachada Este del oratorio de Abd alRahman I en la mezquita de Córdoba", en Cuadernos de Madinat al-Zahrā', 4, Córdoba, 1999, pp. 175-209, especial. p. 182; figs. 1-11, láms. I-XII.

19 A. Fernández-Puertas, "La decoración de las ventanas de la Bāb al-Uzarā’ según dos dibujos de don Félix Hernández Giménez", en Cuadernos de la Alhambra, 15-17, Granada, 1979-1981, pp. 165-210, figs. 1-56, láms. I-XXVIII, especial. pp. 197-200, figs. 41, 42, lám. XXVa, b.

20 A. FernándeZ-Puertas, "La decoración”, pp. 195-197, figs. 37-40, láms. XXII-XXIV.

21 En el Museo de dicha ciudad hasta la guerra de 2003, pues hoy desconozco su paradero.

22 K. A. C. Creswell, Early Muslim Architecture, Part Two, pp. 35-37, fig. 26, láms. Ia-e.

${ }^{23}$ R. W. Hamilton, Khirbat al-Mafjar. An Arabian Mansion in the Jordan Valley, Oxford, 1959, pp. XXXIV-4, XXXIX. A. FernÁNDEZ-Puertas, "La decoración”, p. 197, nota 47; figs. 43-44; lám. XXV-c. 
organización del acanto emiral es la típica de la ornamentación del califato cordobés y llegará esquematizada al arte nazarí.

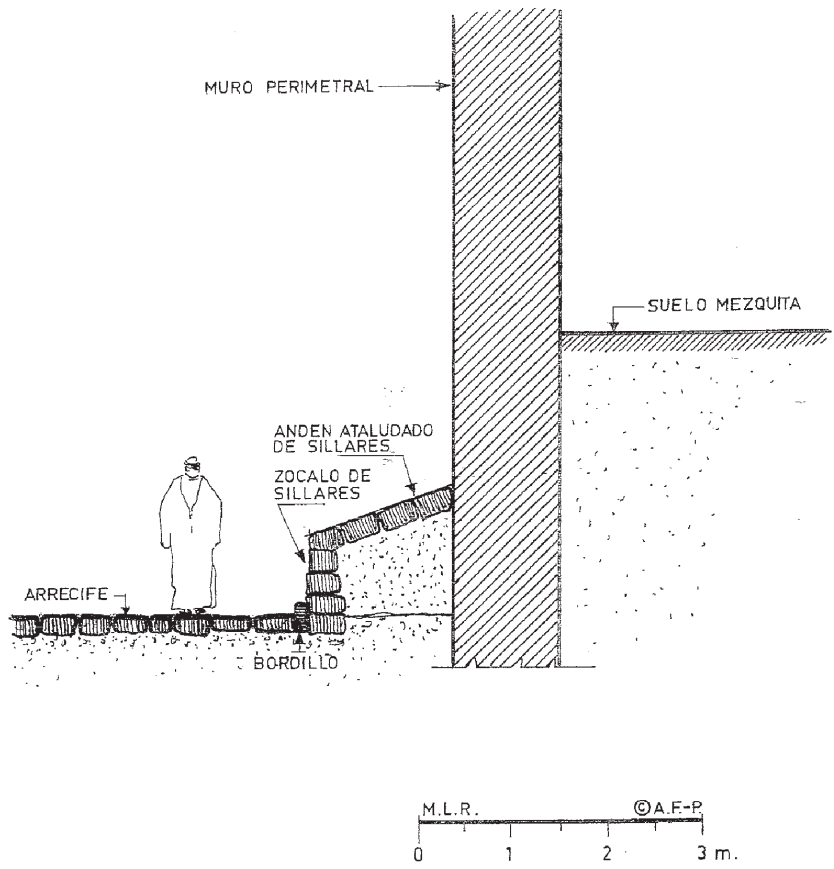

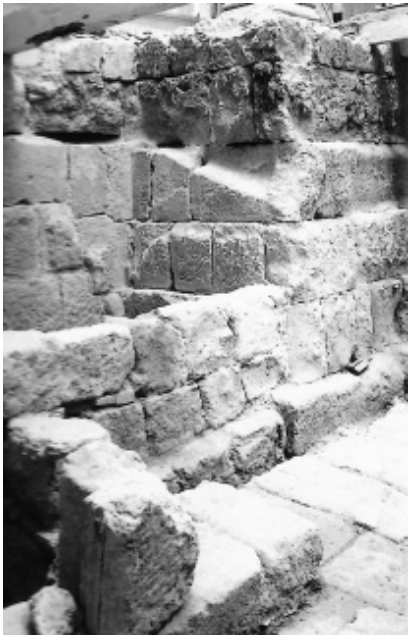

Lám. XII. Contrafuerte y andén ataludado de la mezquita de 'Abd al-Raḥmān I (Foto L. Estaban y M. Pijoan).

Fig. 17

Los precedentes de esta disposición se encuentran ya en el arte romano oriental -como en el decorado de los frisos de Palmira-, pasa a lo bizantino y luego al arte omeya oriental, aunque la hoja todavía no se une en una ristra como en el arte del emirato y califato de Córdoba.

En la restitución que publiqué en 1979 supuse que el nicho del mihrāa descansaba en una columna a cada lado ${ }^{24}$. Hoy pienso que dichas columnas no existieron y que el nicho era de planta de arco de círculo y acababa en la arista de los sillares de ambos lados, con el remate de la charnela y una posible guarnición decorativa, a la cual pudieron pertenecer los otros fragmentos hallados (figs. 18-21) ${ }^{25}$. Este cambio de opinión se debe a que: 1) no han aparecido restos de columnas; 2) los primeros capiteles que se labran en al-Andalus son de época de la ampliación de 'Abd al-Raḥmān II, hacia el año 234/848; 3) las cuatro basas, fustes y capiteles -que luego reutilizará al-Hakam II en su mihrāa (354/965)-, estimo que son las doce piezas labradas para el nicho con cámara interna de la ampliación de ‘Abd al-Raḥmān II (234/848); 4) el miḥrāb situado

${ }^{24}$ A. FernándeZ-Puertas, "La decoración", pp. 197, 199, notas 45, 46; fig. 42; lám. XXV b.

25 Estos fragmentos (figs. 18-21) fueron encontrados en el sector E. en la puerta abierta por 'Abd al-Raḥmān II en el tramo tercero del oratorio del siglo VIII. F. Hernández Giménez los estimó como pertenecientes al decorado de esta puerta junto con los dos fragmentos de la charnela. Nunca le pregunté cómo y dónde exactamente habían aparecido. En mi visita en 1989 a esta excavación, con mi mujer Purificación Marinetto Sánchez y David Castillejo, nos acompañó un empleado que me asignó el Cabildo y fue cuando vimos que en la excavación había un fragmento decorado del que tomé fotografías y ofrezco dibujo en la figura 21. A petición mía fue sacado de allí para su protección y exposición. 
en la nave central del siglo VIII siguió la tradición de nicho de arco de círculo con venera. Esta solución se ve en los relieves visigodos y en tableros y decoración omeya oriental. Así aparece en el nicho de la ventana del testero de la cabecera de la Vera Cruz de Marmelar en Alto Alentejo, Portugal (lám. XIII) y en el nicho marmóreo hallado en la catedral de Badajoz (fig. 22). El tema de la charnela bajo un arco de medio punto o un frontón triangular, aparece en un fragmento de cancel del siglo VII que se guarda en la mezquita de Córdoba (fig. 23) ${ }^{26}$.

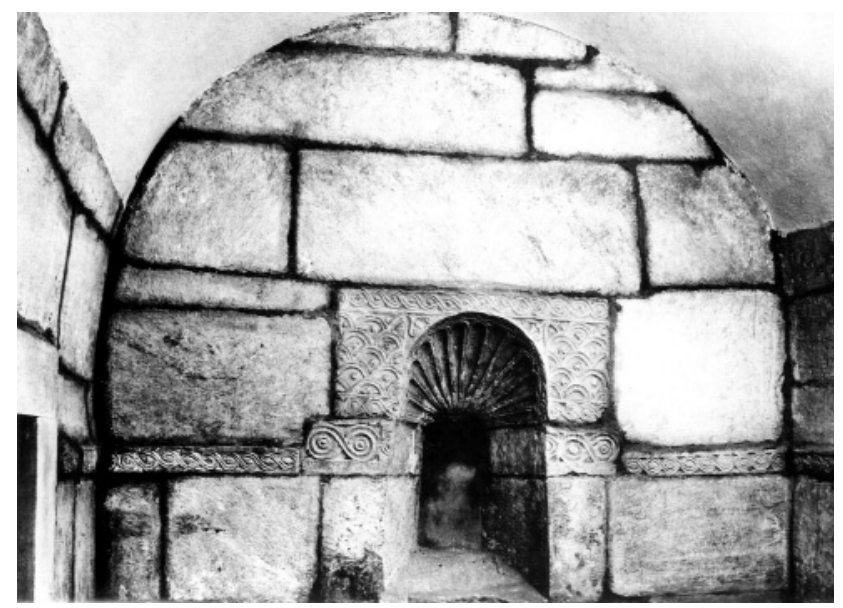

Lám. XIII. Ventana abocinada con la charnela en la Vera Cruz de Marmelar (Alto Alentejo, Portugal) (Foto H. Schlunk y T. Hauschild).

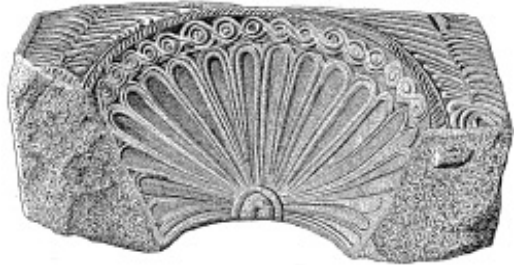

Fig. 22

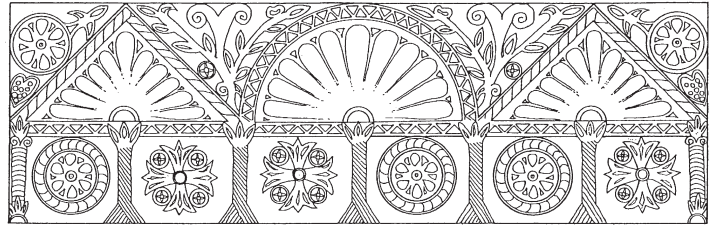

Fig. 23

Éste, a mayor tamaño, fue el esquema del mihrāb del siglo VIII ${ }^{27}$. La pieza de la clave de la charnela fue un sillar dispuesto en tabla con un largo de $45 \mathrm{~cm}$. de izquierda a derecha, un alto de $25 \mathrm{~cm}$. y un grueso de $49 \mathrm{~cm}$. con marca de cal a los $40 \mathrm{~cm}$. (fig. 16). Es decir, estuvo saliente

${ }^{26}$ Helmut SchlunK y Theodor Hauschild, Hispania Antiqua. Die Denkmäler der frühchristlichen und westgotischen Zeit, Verlag Philipp von Zabern, Mainz am Rhein, 1978, pp. 63-65, fig. 43.

27 Véase A. FernándeZ-PuERTAS, “La decoración”, pp. 195-199, figs. 37-42, láms. XXII-XXV. Los otros dos fragmentos con decoración de acanto corresponden a sendas piezas laterales de diferentes arcos; una tiene un largo (fondo) de $34 \mathrm{cms}$. por un lado de $67 \mathrm{~cm}$. y un grueso (ancho) de $57 \mathrm{cms}$. La otra pieza lateral se decora con acanto diferente y más fino de labra. Tiene un largo (fondo) de $40 \mathrm{~cm}$., un alto de $52 \mathrm{~cm}$. y un grueso (ancho) de 25,5 cm. Estas medidas, tal cual aparecen, me han sido proporcionadas por el amigo y colega P. Marfil Ruiz en conversación telefónica mientras él las estaba tomando. Le expreso aquí mi gratitud por ello. 
hacia la cara interna del muro de la qibla. Estimo que los otros restos decorativos hallados formaron parte de otra guarnición decorativa de otro nicho de miḥrāb (figs. 18-21).

En los fragmentos que pienso que formaron el mihrāb de la mezquita de 'Abd al-Raḥmān I, la charnela quizá tuvo el valor simbólico de agua de vida eterna, así como el acanto, planta que siempre vuelve a renacer.

Referente a los otros fragmentos hallados, son piezas diferentes en dimensiones y talla. Cabe la posibilidad, como apuntan M. Gómez-Moreno y L. Torres Balbás, que hubo más de un mihrāāb en la mezquita, el cual pudiera estar desplazado del axial, como en la mezquita de Damasco hecha por al-Walīd I (86-97/705-715 $)^{28}$. No se conoce crónica árabe que respalde esta hipótesis. Si se acepta esta idea ¿cómo sería el mị̂rāb - o mih̆rābs - secundario? Los fragmentos demuestran ser de arcos distintos en curvatura y finura de labra. Es posible que de haber habido un mihrāa descentrado pudiera tener una guarnición ornamental y ser de fondo plano, es decir, sin hueco en la pared, por lo que no necesitaba charnela. Esta forma arquitectónica explicaría que al-Rāzī -en los Anales del califa al-Ḥakam II recogidos por Ibn Ḥayyān ${ }^{29}$ - denomina como miḥrābs los arcos ciegos de herradura que centran el fondo de las tres naves del sector basilical de al-Maŷlis al-Šarqī, Salón Oriental (conocido por Salón Rico), en la ciudad palatina de al-Zahrā', construido entre 342-245/953-957 por 'Abd al-Rahmān III, bajo la dirección de su fatà y liberto Šunayf. Según el cronista, el califa se sentaba sobre una tarima delante del mihrāb de la nave central rodeado de sus tres hermanos a izquierda y derecha según el protocolo de su edad.

Fecha de recepción: 15-XII-2007

Fecha de aceptación: 13-III-2008

\footnotetext{
${ }^{28}$ K. A. C. Creswell, Early Muslim Arquitecture. Umayyads A.D. 622-750, 2. a edición en dos partes, Vol. I, Part I, Clarendon Press, Oxford, 1969, p. 158, fig. 81 y pp. 169-173, fig. 89.

${ }^{29}$ Emilio García Gómez, Anales palatinos del Califa de Córdoba al-Hakam II por 'Isà ibn Aḥmad al-Rāzī, Madrid, 1967.
}

AEA, LXXXI, 324, octUBRE-DICIEMBRE 2008, 333-356, ISSN: 0004-0428 